\title{
An analysis of three curriculum approaches to teaching English in public sector schools
}

\section{Kathleen Graves}

University of Michigan, Ann Arbor, USA

gravesk@umich.edu

\section{Sue Garton}

Aston University, Birmingham, UK

s.garton@aston.ac.uk

\begin{abstract}
:
This article explores three current, influential ELT curriculum approaches to the teaching of English in public sector schools at the primary and secondary level and how the theory of each approach translates into curriculum practice. These approaches are Communicative Language Teaching (CLT), genre-based pedagogy, and Content and Language Integrated Learning (CLIL). For consistency across approaches, the theoretical underpinnings of each will be briefly described according to a matrix of curriculum factors including:

- the view of language and language acquisition underlying the approach,

- how learners' needs are construed

- the nature of the content and materials

- the teacher's role

- the context

- how language is assessed

This is followed by a discussion of research on how each approach is implemented in primary and secondary contexts, the extent to which the theory is put into practice and factors that influence its success in the classroom. Implications for the future of curriculum development in ELT will be discussed. These implications address the viability of CLT in primary and secondary schools, the role of knowledge about language in curriculum implementation, and teacher roles and identity.
\end{abstract}


Kathleen Graves is Associate Professor of Education Practice at the University of Michigan in the United States. She is the editor/author of Teachers as Course Developers and Designing Language Courses, co-editor with Lucilla Lopriore of Developing a new curriculum for school age learners, co-editor with Sue Garton of International Perspectives on Materials in ELT, and the series editor of TESOL's Language Curriculum Development series. Her research focuses on the role of teachers in curriculum and supporting teachers' professional development as the key to successful educational reform.

\section{Kathleen Graves}

School of Education Room 3117A

610 East University

Ann Arbor, MI 48109 USA

Sue Garton is Reader in Applied Linguistics at Aston University, Birmingham, UK, where she teaches TESOL courses to both undergraduate and postgraduate students. She has published widely in the area of teaching English to young learners and materials in ELT. She is series editor, with Fiona Copland, of International Perspectives on English Language Teaching (Palgrave Macmillan) and co-editor with Kathleen Graves of International Perspectives on Materials in ELT.

\section{Sue Garton}

School of Languages and Social Sciences

Aston University

Aston Triangle

Birmingham B4 7ET

UK

\section{Introduction}


This review will focus on three approaches to curriculum currently used to teach English as a second, foreign or additional language in public sector primary and secondary schools: communicative language teaching (CLT), genre-based pedagogy, and content and language integrated learning (CLIL). By curriculum approaches we mean both the intended curriculum--understandings of what is to be learnt and how--as well as the enacted curriculum--how these understandings are enacted (or not) in the classroom. These approaches have been chosen for three reasons. First, they represent important differences in how English is viewed and taught that may shed light on their effectiveness; second, they are currently in use in schools due to national policy and/or local support in different parts of the world; third, there is an available body of research for each that explains both the theories behind the approach and how it has been implemented. The adoption of any curricular approach is determined by a range of factors. As such, the choice of these approaches does not indicate a particular endorsement of them; nor does the exclusion of others such as grammar translation, taskbased, or project-based approaches indicate that they are not worthy of study. As will be discussed, grammar plays a role in both CLT and genre-based pedagogy, tasks play a role in CLT and CLIL, and projects have the potential to interweave the three approaches.

We have chosen to focus on English because its status as the global language of access to social, economic and educational participation makes it the most commonly taught language (Graddol 2006). Economic, social and political forces that are responsible for the spread of English globally have changed educational cultures worldwide, through for example, the introduction of languages into primary school and changes in approaches to language teaching and learning (Enever \& Moon 2009). These changes also include the so-called BANA countries (Britain, Australasia, North America), where the number of students for whom English is a second or additional language continues to grow at all levels. According to an article recently published in Education Week, $10 \%$ of the US student population was made up of English Language Learners in the 2012-13 school year (Vander Ark 2016). However, while English is now a global language, this does not mean that what is taught in English classrooms is by any means homogenous (Modiano 2009). 
On the other hand, we cannot ignore the increasing criticism of the spread and dominance of English, and in particular the political and social implications. A number of writers have challenged understandings of the place of English and whose interests the rise of English serves (see, for example, Block, Gray \& Holborow 2012; Clark 2013). Such critical views of English have led to calls for a more plurilinguistic view of language curricula. In Europe, for example, the European Commission aims for all citizens to be able "to communicate in two languages in addition to their mother tongue" through the introduction of a second or third foreign language into the school curriculum. CLIL approaches may be used to encourage the use of heritage or community languages for learning alongside English (Coyle, Holmes \& King 2009). However, evidence seems to suggest that English continues to dominate. For example, according to Eurydice, the Education Information Network in Europe, 14 of the 27 EU members mandate English as the first foreign language to be learnt and in 2009/10 $73 \%$ of children in primary school were learning English. ${ }^{2}$

The world of English language teaching encompasses distinct domains: groups of people and contexts, each with its own set of purposes and constraints. How English is taught varies greatly among them. For the purposes of the review, we will focus on English in the state school sector at both primary and secondary level. This is a huge domain with great variation, depending on the extent to which English is an official language, an unofficial alternate language of the country, as in Sweden or Bahrain, or a foreign language, as in Vietnam or Italy. Although it is difficult to get accurate statistics, we focus on the state school sector because this is where the majority of young people around the world will learn languages, overwhelmingly English, and where most teachers will teach them. According to Eurostat, $94.1 \%$ of EU students in secondary school were studying English as a foreign language in $2014 .^{3}$

1 http://www.europarl.europa.eu/atyourservice/en/displayFtu.html?ftuId=FTU_5.13.6.html 2 eacea.ec.europa.eu/education/eurydice/documents/key_data_series/143EN.pdf

3 (http://ec.europa.eu/eurostat/statisticsexplained/index.php/Foreign_language learning_st atistics. 
It is also the state school sector that has witnessed the relatively recent introduction of the three approaches to curriculum that are the focus of this review, with each one gaining particular popularity in a different part or parts of the world. We would say, therefore, that the English language curriculum is dynamic and shifting and thus that it is a propitious time to examine current trends and issues.

\section{The curriculum framework}

In order to present the theory underlying each of the three approaches in the same way and to have a lens through which to understand and analyze it in practice we will use a curriculum framework. The framework (see Figure 1) is broadly based on the American curriculum scholar, Joseph Schwab's five ‘curriculum commonplaces' (1973), which he originally developed in order to identify the types of experience necessary to undertake effective curriculum revision in schools.

The five commonplaces are:

- Subject matter - what is to be learnt

- Learners - who the learners are, their age, background

- Teachers - who the teachers are and what they believe, know or can do

- Milieus - the nested, expanding contexts in which learning and teaching occur including the classroom, the school, and wider community

- Curriculum-making - the coordination of the above four bodies of experience in order to create workable 'embodiments' of the curriculum

Schwab proposed the commonplaces as a way to counteract the prevailing view that subject matter (as conveyed by experts) is the core of a curriculum. By taking into account learners, teachers, and contexts, subject matter could be made practical through curriculum making. Our framework largely follows Schwab's with some modifications and the addition of assessment.

1. The subject matter and how it is learnt:

--View of language

--View of classroom language acquisition 
2. Needs and roles of learners

3. Role of the teacher

4. Role of context

5. Design and organisation of the curriculum

--Organisation and progression of the curriculum

--Types of materials and activities

6. Assessment

Figure 1. Framework for curriculum analysis

\subsection{Subject matter}

Language, in the sense that it is a resource we use for meaning making in all aspects of our lives, is not intrinsically an educational subject matter. In order to be taught and learnt in a classroom, language must be turned into curriculum content. Graves (2016) has identified three waves of language as curriculum content. In the first 'linguistic' wave, language is a set of linguistic systems - the formal or structural view of language. In the second 'communicative' wave, language is viewed as communication and the aim of learning is to develop a generalized communicative competence-what we generally call CLT. In the third wave, language is a resource for meaning making contingent on a context of use - thus the emphasis is on language in relation to texts, projects and/or other subject content.

Second and third wave approaches, which are the subject of this review, are concerned with language use. In other words, the aim of learning language in classrooms is to use it for some purposes, not simply to learn about it. For this reason, we have subdivided this category into both a view of language and a view of how that language is acquired in the classroom. We will refer to it as classroom language acquisition because we are looking at school age learners for whom English is not their home language and how they learn English in schools.

\subsection{Learners - their needs and roles}


This category identifies the learners as those in primary and secondary schools, for whom English is a language other than the one they use at home, and therefore one that they are learning in the classroom. Contrary to most other 'foreign languages', in many contexts

English is widely available and may be used by school-age learners outside the classroom via the media, music, the internet, and online gaming communities. Thus learners' needs will vary, depending on the context in which they are learning and how the approach defines their needs. The needs of an English learner in an English-medium school will be different from those of a learner who studies English as a 'subject language' (LarsenFreeman \& Freeman 2008) four hours a week. Their roles will also vary depending on what the approach requires.

\subsection{Teachers - their roles}

This category identifies teachers as those who teach English learners. This includes both designated English teachers (who may or may not be trained as English teachers) and subject matter teachers whose students include English learners or who teach their subject in English with a dual focus on subject matter and language. Their roles will differ depending on the context and on what the approach requires.

\subsection{Milieus}

We use the more common term 'context' in our framework. By context we adhere closely to Schwab's conception of nested, expanding contexts. The nested nature of socioeducational contexts make 'context' in English language teaching difficult to define. In the last Language Teaching review of curriculum, Graves (2008) made a distinction between contexts in which the target language is embedded (the target language in the present article being English), and contexts in which it is removed. In target language embedded contexts English is the language of all school subjects and the wider society. In target language removed contexts English is a subject language, where other subjects are taught in the mother tongue or national language, which is also the dominant language in domains outside of the school.

In terms of English, this binary distinction needs to be replaced by a continuum, with one end being target language removed contexts as described above--most state 
schools in China or Brazil would fit at this end of the continuum. The other end is target language embedded contexts, of which state schools in Australia or the US would be examples. In the middle of the continuum are contexts in which English is the language of school but not the dominant language outside of school. English medium secondary schools in Hong Kong would be an example of this context. Between the subject language end and the middle are contexts where English is both taught as a 'subject language' and is also the medium for instruction in some subjects.

\subsection{Curriculum-making}

Schwab defined curriculum making as creating and trialing 'the concrete embodiments, the material objects, which are the indispensable constituents of a curriculum' (Schwab 1973: 505). These 'embodiments' realize the purposes and values of the curriculum. We see this in more prosaic terms as the overall design and progression of the curriculum, i.e. how curriculum content is organised and progresses over time in order to lead to the kind of learning aimed for in the approach. We also include in this the types of materials and activities that contribute to learning in the approach.

\subsection{Assessment}

We have added a component to the framework, assessment, by which we mean how success is determined as defined by the curricular approach. Assessment is concerned with documenting the effectiveness of the approach within the classroom-what counts as learning and how that learning is assessed.

In the following sections, for each approach, we will apply the curriculum framework in order to first describe the theory that underlies it and then review research on its implementation in schools. After discussing each approach separately, we will discuss similarities and differences among them and what we might learn that can point to effective teaching and learning of English in schools. We will close with suggestions for future research.

\section{Communicative language teaching}

\subsection{Introduction}


The late $20^{\text {th }}$ century saw a huge movement for reform of language teaching in the state school sector in a large number of counties in the world, in particular in Asia. The reform was both structural, with the introduction of languages into the primary school curriculum, and in content, with the introduction of communicative curricula to replace more traditional grammar-based approaches at both primary and secondary levels.

The most common reasons cited for these reforms, and for the adoption of communicative language curricula in particular, are globalization and the perceived need for an English-speaking population in order to compete in the global economy as well as to contribute to national development through international exchanges in a variety of fields such as business and technology (see, for example, Lin 2010; Butler 2011; Hamid \& Honan 2012).

One of the difficulties with any discussion of communicative curricula, and especially communicative language teaching (CLT) lies in the lack of consensus as to exactly what it is and what it consists of, in spite of (or perhaps due to) the very large volume of writing and research on the subject, going back to the 1980's. For the purposes of this review, what follows will focus primarily on work published since 2008 and will refer to earlier work when it is cited in recent publications. This will enable us to see how communicative curricula and CLT have been viewed in recent years.

Lin (2010) sees CLT as an answer to the 'how' (ie a method) to teach the 'what' of a notional/functional syllabus. Richards (2013, citing Trim 2012), on the other hand, talks of a new communicative syllabus, replacing the older grammar-based or structural syllabus. He makes the case that CLT prioritizes syllabus over methodology and quotes Clark as stating that the influence of CLT on FL curriculum "... has given rise to the audio-lingual, audio-visual/situational, topic-based and functional notional approach to foreign language learning” (Clark 1987:23 cited in Richards 2013:12). Although separating method from syllabus is rarely clear-cut in CLT as the two can often be seen to overlap, for the purposes of this article, we will mainly focus on the communicative syllabus because that is the view generally adopted by governments in formulating their language-in-education policies.

Task-based language teaching (TBLT) is seen by some as a version of CLT. Butler (2011) for example, maintains that 'task' has come to replace 'communicative 
activity' in curriculum specification. However, she also cites Kumaravadivelu's (2006) position that TBLT is not associated with a particular method, but rather should be seen as "curricular content". Richards, on the other hand, in his distinction between backward, central and forward curriculum design (Richards 2013) gives CLT as an example of forward design, but gives versions of task-based language teaching (TBLT) as examples of either central or backward design, thereby situating TBLT as distinct from CLT.

Therefore, understandings of CLT are by no means universal. Moreover, it is noticeable that governments, when introducing curricula reform, rarely define what they mean by 'communicative'. In this review, we will consider TBLT to be 'the latest realization of CLT' (Nunan 2003: 606), partly because governments explicitly promoting task-based curricula do not appear to make any distinction and because, as Butler (2011) notes, the challenges in implementing such curricula are essentially the same as for CLT.

\subsection{Curriculum Framework}

\subsubsection{The subject matter and how it is learnt}

View of language

Butler (2011, citing Richards \& Rodgers 2001 and Savignon 2005) notes that CLT curricula are based on developing learners' communicative competence in social situations rather than mastery of linguistic forms while Breen \& Candlin (1980: 90 cited in Seargeant, 2008:136) state that 'the communicative curriculum defines language learning as learning how to communicate as a member of a particular socio-cultural group'.

The central notion, therefore, is that of communicative competence and the origins of CLT can be traced back to Dell Hymes' work, amongst others, and his oft-cited quote that 'there are rules of use without which the rules of grammar would be useless' (1972: 278). Hymes' work contributed to a new understanding of the nature of language (Richards 2013) and together with Canale and Swain's model of communicative competence (Canale \& Swain 1980; Canale 1983) led to a view of language learning based not only on grammatical competence, but also on sociolinguistic, discourse and strategic competences.

Therefore communicative approaches to curriculum take a holistic view of 
language, which is used to make meaning in specific contexts.

How language is acquired in the classroom

As noted above, CLT has developed into the dominant approach to language teaching in many parts of the world, especially in the state school and private sectors, but over time it has also come to mean many things to many people. Butler (2011:37) argues:

CLT is broadly based on theories of communicative competence and second language learning. However, this theoretical broadness has invited various interpretations of CLT and led to some variety in its realization in practice.

Nevertheless, there is general agreement that classroom language acquisition is based on developing learners' communicative competence, which is realized through a set of classroom principles:

- language should be authentic and with an emphasis on meaning

- there should be a balance of fluency and accuracy

- both productive and receptive skills should be developed

- language forms are not excluded but should be presented in context

- materials should be authentic

- the target language should be used in the classroom by both teachers and learners whenever possible

- learning should be active and collaborative

(adapted from Brown (2007) and Jacobs \& Farrell (2001), cited in Prapaisit de Segovia \& Hardison 2008).

\subsubsection{Needs and roles of learners}

Communicative curricula should be based on the needs of the learners (Brown 2007; Nunan 1989, cited in Prapaisit de Segovia \& Hardison 2008). In many government curriculum reforms 'need' is defined as needing to communicate effectively in the target language. However, learners in state schools in different contexts, or even in the same classroom, may have very different needs, or no clearly defined needs at all (Stelma 2009). Designing a curriculum based on needs which are neither well-defined or easily 
identifiable is clearly problematic.

A basic tenet of CLT is the learner-centred classroom, based on collaboration and cooperation, with learners as active participants and an emphasis on the co-construction of knowledge (Prapaisit de Segovia \& Hardison 2008). Therefore, learners should use language meaningfully through interaction (Butler 2011) and negotiate meaning while controlling their own learning use through a range of strategies (Adamson \& Yin 2008). The emphasis should be on pair, group or individual work to complete tasks (Hamid \& Honan 2012).

\subsubsection{Role of the teacher}

The role of the teacher in CLT is typically that of facilitator and guide in the learners' acquisition of communicative competence, through the engagement of learners in their own learning process (Brown 2007; Jacobs \& Farrell 2001, cited in Prapaisit de Segovia \& Hardison 2008; Lin 2010). The teacher should ensure a rich language environment providing meaningful input and giving opportunities to use language in a meaningful and creative way through communicative activities or tasks (Adamson \& Yin 2008; Butler 2011).

Butler (2011) distinguishes between strong and weak versions of CLT. In the strong version, the teacher is simply facilitating a natural process of language acquisition as learners develop their own awareness of the language. In weaker versions, the teacher takes a more active role in introducing more structured, meaning-focused activities. Strong versions of CLT would seem to be relatively rare in practice.

\subsubsection{Role of context}

The role of context is difficult to define in CLT. Most countries where CLT forms the basis of the English curriculum are target-language removed (Graves 2008). In principle, CLT is based on learner needs, and governments have introduced communicative language curricula to achieve economic and development goals, but these goals are often far-removed from the daily lives of school children.

Therefore, while the aim of CLT is to teach appropriate language use in specific situations, where English is taught for no particular purpose other than as a school 
subject, context-dependent variations in language use are clearly too numerous to identify and impossible to teach. As Stelma (2009: 54) notes:

The range of variability extends not only to the real-time unfolding of situations, but also to variation in patterns of communication across and within both small cultures (cohesive groups of people in particular societal settings) and large national cultures.

An examination of any of the popular coursebooks currently in use, generally based on weak versions of CLT, will show that one consequence of the lack of a specific purpose for learning is that grammar rules still tend to be the main organizing principle of the CLT curriculum.

\subsubsection{Design and organisation of the curriculum}

Organisation and progression of the curriculum

The shift in the 1970's from a structural view of language to a view of language as communicative competence led the Council of Europe to elaborate a notional functional syllabus, which described a threshold level of language use for all languages in Europe (See Savignon 2008; Richards 2013 for more detail) and which was to form the basis of the communicative curriculum.

The influence of the notional functional syllabus can still be seen today, but a glance at any of the internationally produced coursebooks which claim to be communicative will evidence an eclectic approach to curriculum organisation including not only functions and notions, but also topics, skills, grammar and vocabulary, to which can sometimes be added learning strategies and intercultural awareness. However, grammar tends to be the main determiner of organisation for older learners, as noted above, while at primary level, it is topics.

\section{Types of materials and activities}

According to the principles of CLT, materials should be 'authentic', although the concept of authenticity in language teaching is extremely complex (see Gilmore, 2007 for a discussion). The definition that is usually used is that of materials that have been produced for reasons other than language teaching. Given the difficulties in identifying learner needs, materials selection needs to be based on alternative criteria. Tomlinson 
(2011) suggests, beyond linguistic considerations, that materials should achieve impact and make learners feel at ease and develop their confidence. Learners' interests and the potential for personalization (Hardman \& A-Rahman 2014) are also considerations.

Materials are used to achieve meaningful communication in the target language through communicative activities. Johnson (1982, cited in Stelma, 2009) identifies five principles of such activities:

- Information transfer

- Information gap

- Jigsaw

- Task dependency

- Correction of content

These principles are then applied to promote active learning though types of tasks such as ordering, sorting and sequencing, matching, categorizing, prioritizing and ranking and problem-solving, amongst many others (Edge \& Garton 2009).

3.2.6 Assessment: How success is measured; how learning/language is assessed Assessment is perhaps the most neglected aspect of discussions of communicative curricula. While there has been some recent interest in CLT and teacher-based assessment, with TESOL Quarterly publishing a special issue in 2009 (Davison \& Leung 2009), it is the case that very few teachers in the school sector have the opportunity to undertake their own assessments and testing remains one of the biggest problems in the implementation of CLT.

In one of the few recent publications to address communicative testing, Morrow (2012: 140) notes that essentially a communicative test aims to assess what learners can do with a language rather than what they know about its systems - testing learners' use rather than usage. He then goes on to show why testing use is challenging, arguing that communicative testing becomes not a test of language but of skills (reading, writing, speaking and listening) and learners' abilities to do things with the language, which makes it extremely difficult to establish what to test and how (see Morrow 2012 for details). Morrow concludes that there are, however, some features of mainstream tests that derive from the original conceptions of communicative language testing dating back 
to the 1970s and 1980s. These include speaking tests with candidates tested in pairs; writing and speaking tests based on tasks with a specific purpose; the use of criteria for evaluation.

A major development in communicative testing was the publication of the Common European Framework of Reference for Languages by the Council of Europe (2001, cited in Kantarcioglŭ and Papageorgiou, 2012). Originally intended to inform language syllabi, textbooks and examinations, the CEFR was very quickly taken up by the major providers of international examinations, such as Cambridge, who mapped their tests onto the levels. However, its influence on national state exams remains uneven. While Alderson (2007) notes that the Framework formed the basis for the development of language assessment in post-communist Eastern Europe, Little (2007) claims that its impact on school examinations is limited.

\subsection{Communicative language teaching in practice}

In this section we look at the implementation of communicative curricula in the state school sector with a particular focus on Asia. We focus on this geographical area because a great deal of research on CLT implementation has been carried out in East Asian contexts, possibly because the move to a national curriculum based on communicative competence represented a sudden and major shift away from previous structural and grammar-based curricula. Given the ever-increasing number of publications on this topic, any overview is necessarily selective, but we will cover the common issues identified in implementing CLT in both primary and secondary schools across a number of different East Asian contexts.

The vast majority of the large body of research into language curriculum reform and its implementation across East Asia points to the gap between curriculum policy and classroom practice. The gaps have been identified in global studies (see for example Enever \& Moon, 2009; Copland, Garton and Burns, 2014), in regional studies (see, for example, Baldauf et al. 2011; Butler 2011) and in studies of specific countries such as mainland China (Yan \& He 2012; Zhang \& Liu 2014), Hong Kong (Adamson \& Yin 2008), Japan (Seargeant 2008; Gaynor 2014), Malaysia (Ali, Hamid \& Moni 2011; Hardman \& A-Rahman 2014), South Korea (Kang 2008; Garton 2014), Taiwan (Chen 
2011), Thailand (Baker 2008, Prapaisit de Segovia \& Hardison 2008), and Vietnam (Nguyen 2011).

The focus of much of the research has been on the absence of learner-centred classrooms, and especially the persistence of teacher-centred interaction patterns. For example, Prapaisit de Segovia \& Hardison (2008) looked at the implementation in Thailand of the 1996 Development Plan and the 1999 National Education Act which introduced learner-centred teaching for all subjects, with a focus on communicative language skills in English. When the researchers observed classes, they found no evidence of teacher to individual learner or learner-to-learner communicative interaction, seen as essential interaction in communicative classrooms.

In another example, Hardman \& A-Rahman's (2014) study focused on the introduction of the new primary curriculum introduced in Malaysia in 2011. The aim of the reform was 'equip pupils with basic language skills so as to enable them to communicate effectively in a variety of contexts' (260-261). In-service training was offered to teachers to build on CLT approaches which had been introduced in teachers' pre-service training. The training was predicated on a cascade model, but Hardman \& ARahman's (2014) research into classroom practice showed minimal impact. They overwhelmingly found teacher-centred teaching based on traditional interaction patterns.

Research into the reasons underlying the challenges of CLT curriculum implementation faced particularly by primary school teachers was reviewed in Garton, Copland \& Burns (2011). The research cited in that study was primarily from the early 2000s, yet this current review of studies since 2008 seems to show that little has changed.

The first set of challenges concern socio-cultural issues. It is often noted that communicative language teaching is a western-based methodology which does not take into consideration local differences and constraints (Lin 2010). It is argued, for example, that the role of the teacher in communicative approaches makes CLT inappropriate in some contexts where the teacher is seen as a knowledgeable authority (Baker 2008; Lin 2010; Hamid \& Honan 2012). Butler (2011) points to the ethnocentricity of CLT, but she also criticizes cultural arguments such as the incompatibility of CLT with Confucianism as over-simplistic and ignoring differences within countries and even from one school to another. However, the local social context, taking into consideration socio-cultural and 
socio-political factors, cannot be ignored in identifying appropriate approaches to language teaching (Lin, 2010; Hamid \& Honan, 2012). Baker (2008) for example, cites a number of sources that argue for the need to develop a local version of CLT in Thailand.

Another issue with CLT is that it is predicated on native-speaker norms and this may be neither desirable nor attainable (Lin 2010). Both Seargeant (2008) and Butler (2011) point to the fact that the term 'communication' is rarely problematized and yet it does not have universal meaning or value. As Seargeant (2008:137) notes:

...the communicative curriculum becomes not simply about learning a particular foreign language, but learning the specific values and ideologies of interpersonal interaction that are associated with that language.

These values and ideologies are then presented as universal and lead to a 'deficit problem' for both teachers and learners.

The introduction of communicative curricula may also clash with teachers' beliefs and experience (Zhang \& Liu, 2014). Adamson \& Yin (2008) reported that teachers in Hong Kong were satisfied with their current practices and did not see the point of introducing TBLT, although they did incorporate elements of it into their practice. Seargeant (2008) notes that there is a general assumption that previous practices are incompatible with new approaches, but he questions whether that is the case, while Lin (2010) maintains that so-called 'traditional' activities such as drills, translation and use of L1 may be appropriate in certain contexts and also have their place in communicative classrooms.

There are also a number of practical challenges to the introduction of communicative curricula, three of which can perhaps be identified as the major obstacles to successful implementation. These are: a. the impact of the national examination system b. the lack of teacher training, often with the consequent lack of understanding of the new curriculum, and c. teachers' actual or perceived levels of English proficiency.

National standardized tests, or college entry tests have a major negative impact on the implementation of communicative curricula as exams remain grammar-based in many countries (Baker 2008; Prapaisit de Segovia \& Hardison 2008; Seargeant 2008; Lin 2010; Butler 2011). Seargeant (2008) points out that the exam system in Japan is central to the education system and exerts a major influence on it, while the teachers in Hardman \& A- 
Rahman's (2014) study justified their use of traditional teacher-centred interaction patterns by their need to cover the exam syllabus. Butler (2011) notes that even where teachers have the freedom to carry out their own assessments, they do not necessarily have the time, resources or support to do so.

Lack of training for teachers (Lin 2010; Butler 2011; Hamid \& Honan 2012) or training that is inadequate for developing a real understanding of innovation (Adamson $\&$ Yin 2008; Baker 2008; Hardman \& A-Rahman 2014) constitute a major obstacle to the successful implementation of communicative curricula. The Malaysian primary school teachers in Hardman \& A-Rahman's (2014) study, for example, were aware of songs, games and so on as suitable activities for primary school children, but they did not know how such activities could be integrated into achieving learning outcomes. The Thai teachers in Prapaisit de Segovia \& Hardison's (2008) study felt that their training was often theoretical and they did not have adequate practical information to implement the new curriculum. Inadequate or inappropriate training means that teachers are often unaware of or hold misconceptions about the principles underlying the communicative curriculum (Hardman \& A-Rahman 2014). Common misconceptions are, for example, that the emphasis should be on speaking and that only English should be used in the classroom (Adamson \& Yin 2008; Kang 2008; Butler 2011). Moreover, other stakeholders such as school authorities or parents may also lack understanding of the new curriculum.

Teachers' low proficiency level or their lack of confidence in their English ability are consistently identified as obstacles to successful curriculum implementation (Adamson \& Yin 2008; Baker 2008; Prapaisit de Segovia \& Hardison 2008; Ahn 2011; Butler 2011; Hamid \& Honan 2012). Baker (2008: 138) cites local sources that $80 \%$ of Thai primary English teacher lack any English language qualification and 50\% have inadequate levels of English. Many teachers believe that CLT demands particular classroom procedures, such as teaching in the target language, which causes anxiety and leads to teachers' questioning their competence, particularly their speaking and listening skills.

While the three challenges outlined above can perhaps be considered the major obstacles to successful implementation, researchers have identified a number of other 
constraints. For example, while pair work and group work are seen as central tenets of CLT, the reality in many contexts is large classes, or very large classes (Baker 2008; Lin 2010; Butler 2011). This reality leads teachers to believe it is difficult or impossible to introduce learner-centred teaching, in particular because of difficulties in classroom management (Adamson \& Yin 2008; Butler 2011). Alongside large classes, teachers also face lack of support and financial resources (Adamson \& Yin 2008; Prapaisit de Segovia \& Hardison 2008) from authorities at all levels; the limited number of hours given to English in the curriculum (Butler 2011); heavy teaching loads (Lin 2010), together with the demands of administrative and extra-curricular duties. Such challenges and constraints are not limited to CLT, of course, and tend to be part of any educational innovation and it is likely that such challenges will emerge more prominently in studies into the other areas of language curriculum reform discussed in this review as the body of research on implementation grows.

Perceptions of learners and of their needs are also given by teachers as a justification for maintaining their traditional practices. Learners' limited English proficiency, together with their low levels of motivation, partly due to the lack of opportunities to use English outside the classroom are all seen as challenges to the implementation of communicative curricula (Prapaisit de Segovia \& Hardison 2008; Lin 2010; Butler 2011; Hamid \& Honan 2012).

Materials are another important factor, with the lack of availability of appropriate materials in many countries (Prapaisit de Segovia \& Hardison 2008). Even when suitable materials are available, teachers might have difficulties in selecting them (Butler 2011), they might not be used in the classroom (Inal 2009) or they are not used in the way intended. In some contexts, such as Thailand, for example, teachers may be expected to prepare their own materials but they have neither the time nor the expertise to do so (Prapaisit de Segovia \& Hardison 2008).

As Butler (2011:42) concludes:

In sum, while CLT has substantially influenced the curricula and syllabus designs in English language teaching in Asia, there exists a substantial discrepancy between policies and actual practices at the classroom level. 


\section{Genre-based pedagogy}

\subsection{Introduction}

Genre-based pedagogy, specifically, the Sydney school of genre-based literacy pedagogy, the most influential genre approach at the primary and secondary level (Rose \& Martin 2012), is rooted in Systemic Functional Linguistics (see e.g. Halliday \& Matthiessen 2004), genre-theory (e.g. Martin 2009) and an explicit pedagogy (e.g. Rothery 1996, Rose 2015). It was originally developed in Australia in the 1980's at a time when the focus in primary schools was on process writing with the result that students, particularly indigenous and migrant learners, learned to write only a very narrow band of genres, and not very well. According to Martin (2009:11),

This limited experience of writing did very little to prepare students for learning across the curriculum in primary school, for writing in the specialized subject areas of secondary school, or for dealing with various community genres they might encounter as the most fluent English speaker of their family.

Thus, as a matter of social justice, a genre approach was introduced. Nearly four decades later, the language architecture of the genre-approach now undergirds the national curriculum for English in Australia (Derewianka 2012).

According to Rose (2015) there have been three phases of genre-pedagogy. During the first phase in the 1980's, the key genres of primary school were identified through curriculum mapping and an explicit pedagogy for teaching those genres was developed. In the second phase in the 1990's, the curriculum mapping extended to secondary school and the workplace and explored the relationship between writing and different types of subject matter knowledge. In the late 1990's, the pedagogy expanded to focus on explicit work on reading in order to develop content knowledge and support writing throughout schooling. Over the years, the approach has been taken up to greater or lesser degrees in a variety of other countries, which will be explored in the second section on the curriculum in practice.

\subsection{Curriculum Framework}

4.2.1 The subject matter and how it is learnt View of language 
Genre-pedagogy is concerned with how language functions as a resource for making meaning. Language is seen to have three meta-functions for creating three types of meaning: an ideational function to describe experience and express ideas; an interpersonal function to create relationships with others; a textual function to manage the flow of what is said or written (Halliday \& Matthiessen 2004). These meanings are realized through texts (Derewianka 2003). Texts are always generated in relation to context, both the larger context of culture and the immediate context of situation.

The context of situation comprises what the text is about, the nature of the relationship with the interlocutor or audience, and how the text is organised. 'These different aspects of the context of situation ... are realized in lexical and grammatical choices.' (Schleppegrell 2004: 46) which together make up the register of the text (Rose $\&$ Martin 2012). In the context of schooling, the grammar of academic registers is different from 'every day' registers, in that 'Academic texts make meanings in ways that are informationally dense and authoritatively presented' (Schleppegrell 2004: 44).

Each culture has recurring types of texts, which are called genres (Martin 2009). Genres represent the values and beliefs of a culture, with some being more valued or prestigious. According to Derewianka, 'In learning the genres of a culture, we are learning how to participate in the new culture' (2003: 142). School genres include procedures, recounts, narratives, explanations, and arguments. Genres evolve so that people can accomplish social purposes (Rose \& Martin 2012) and different genres achieve different purposes. For example, the purpose of a report is to organise information about a topic while the purpose of a recount is to describe what happened. Each genre is 'a staged, goal-oriented, social process' (Martin 2009: 20) in the sense that in order to achieve the purpose, we build up the genre through stages.

How language is acquired in the classroom

\footnotetext{
${ }^{4}$ In Systemic Functional Linguistics what the text is about is referred to as 'field', the relationship between the author of the text and the audience is referred to as 'tenor', and where the text falls on the mode continuum between spoken and written language is its 'mode'.
} 
Language acquisition in genre-pedagogy is a process of learning language, learning through language, and learning about language (Rothery 1989). In the classroom, learners expand their lexical and grammatical resources (learn language), acquire and construct new knowledge and content (learn through language), and discover how language constructs that content (learn about language). They do this by learning to interpret, produce and participate in a variety of school genres or 'knowledge genres' (Rose 2015), appropriate to their age and grade level.

Schleppegrell (2004: 22) points out that:

Much of the knowledge that schooling aims to develop in the child is not available just through everyday experience in the world; it needs to be articulated in ways that abstract from everyday life as children engage in structured experiences that provide new perspectives on the world and enable them to generalize their experience.

Language acquisition thus follows a spiral trajectory from 'every day' understandings of the world, which are constructed through language, to increasingly abstract understandings, which are also constructed through language. Thus, the way language works is made explicit so that students can do this.

The language is made explicit through an apprenticeship model. The model has specific stages through which learners gain increasingly complex understanding and control of subject matter content and related genres through explicit guidance from the teacher. The model, referred to as the teaching cycle (Rothery 1996) or teaching-learning cycle (Rose \& Martin 2012) is described in Section 4.2.5. Language is thus acquired through interactions about subject matter across a 'mode-continuum' (Gibbons 2015), moving from everyday, spoken register to increasingly abstract, written academic register.

\subsubsection{Needs and roles of learners}

Genre-pedagogy was developed as a way to provide disadvantaged learners, including English language learners, with tools to help them unpack and master the genres of schooling. The fundamental learning need is for academic literacy in the broadest sense 
of being able to interpret and construct meaning in a variety of texts as they relate to subject matter.

Regarding role, learners have an active role in the approach as it requires them to use language as they learn it and to operate at high cognitive levels. They are expected to read and analyze examples of each genre and to use metalanguage to do so, and to write versions of the genre appropriate to their grade level in school (Brisk 2015).

\subsubsection{Role of the teacher}

In the broadest sense the teacher's role is to scaffold learners' development of increasingly complex literacy (Gibbons 2009). To do so requires knowledge of genres, ie. their purpose and stages, and knowledge about language, i.e. the lexicogrammatical features that realize them (Brisk 2015.) According to Derewianka (2003: 140), 'The role of the teacher is seen as extending the learners' repertoire of grammatical choices, both in their construction of meaning in texts and in their comprehension of meaning in texts.' In order to do this, teachers also need knowledge of genre-pedagogy - how to orchestrate the curriculum cycle so that learners develop genre-knowledge. The teacher plays an authoritative role in order to make language visible and explicit to learners (Christie 2013). The teacher is thus a curriculum maker, as genre pedagogy entails a great deal of curriculum planning.

\subsubsection{Role of context}

Context plays an essential role in genre pedagogy in the sense that genres are understood as both defining a culture, and as products of it. This symbiotic relationship is evident in the context of schools, where academic genres have evolved. In school, students are socialized into particular schooled discourses, which may vary strikingly from the discourse of home. Genre-pedagogy makes the discourse that constitutes the context visible (Schleppegrell 2004).

4.2.5 Design and organisation of the curriculum Organisation and progression of the curriculum 
The overall curriculum is broadly organised around the subjects and genres of school. Through genre-mapping, educators determine the genres that will be taught at different grade levels, with different subjects, and the lexicogrammatical features that will be explored with each genre (Custance 2006). Work with a particular genre is based on the teaching-learning cycle.

The teaching-learning cycle, which has evolved over time, has three stages: deconstruction [of text], in which students encounter the genre and learn about its purpose, stages and language features; joint construction, in which the class jointly constructs a new example of the genre under the teacher's guidance, and independent construction, in which students write their own individual example of the genre (Rose \& Martin 2012). Accompanying each stage is setting context and building the field, or knowledge of the content. The cycle is iterative, as, for example, texts created by students in the independent construction stage can be used as exemplars in a subsequent deconstruction stage (Brisk 2015).

From the beginning, students are introduced to metalanguage to talk about the genre (Gebhard, Chen \& Britton 2014). In discussing the independent construction of a narrative, for example, a 12-year-old says, 'In my second story I had built up my nominal groups a heap more than in my first story and that gave it more description and I think more tension' (Polias \& Dare 2006:133).

The teaching-learning cycle has been further expanded by Rose \& Martin to include reading (Rose \& Martin 2012; Rose 2015). In an initial 'preparing to read' stage, the teacher explains the meaning of the whole text. The teacher then guides students to understand specific wordings of the text. This is followed by work on writing similar texts through joint rewriting of the same text or construction of a new one, prior to independent writing.

Types of materials and activities

Materials and activities build on students' prior knowledge and are geared to the stages of the teaching-learning cycle (Brisk 2015, Gibbons 2015.) Materials include texts that are exemplars of the genre; graphic, visual, multi-modal and print materials used to understand the content; materials to understand the workings of the genre and its 
lexicogrammatical features, such as graphic organisers, scrambled texts and sentences, texts with certain lexicogrammatical features removed and so on.

4.2.6 Assessment: How success is measured; how learning/language is assessed Success in the genre-pedagogy approach is ultimately measured by how well learners are able to appropriate the genres of schooling. Appropriation of a genre depends on how well learners understand its purpose and stages and the kinds of lexicogrammatical choices that can achieve the purpose; and on their ability to produce or participate in the genre in ways that are appropriate to their age and grade level and to the subject matter. Genres recur throughout schooling, and students become more sophisticated in the lexicogrammatical choices they are able to make as they go through the school years. Because genre features are addressed explicitly, the basis for assessment is also explicit. In that sense, assessment is an ongoing part of the approach and crucial to its success. According to White, Mammone \& Caldwell (2015: 261), A key element of the genre-based pedagogy is the production by students of 'preteaching' and 'post-teaching' texts: writing produced in response to a set topic or an essay question at the commencement of what is typically a term-long teachingand-learning cycle, before the topic and subject matter have been introduced or any text modelling done (the pre-teaching text) and then again at the conclusion of the cycle (the post-teaching text).

These texts are assessed according to specific criteria related to the genre. These criteria (and thus the assessment) move from the text as a whole (how appropriate it is for the context/purpose), before proceeding to a closer look at the discourse level (stages), and then finally moving to grammatical conventions, spelling, punctuation and layout (Brisk 2015, Gibbons 2015, Rose 2015). The criteria, which have guided teaching and learning in the first place, allow teacher and learners to make concrete assessments of progress and achievement as well as of specific areas for remediation.

\subsection{The genre-pedagogy approach in practice}

The practice of genre-pedagogy has gained momentum outside of Australia over the last two decades. It has had an impact on the New Zealand English Curriculum (Dix, 
Cawkwell \& Locke 2011) and through university collaborations with public-sector schools in the United States (e.g. Gebhard et al. 2014, Moore \& Schleppegrell 2014, Brisk 2015.) It informs the English language curriculum of Singapore (Ministry of Education Singapore 2010) and Indonesia (Sukyadi 2014). This section will discuss a selection of reports and research from three contexts, Australia, Hong Kong and Indonesia. They have been chosen to represent three points on a continuum from English-embedded (Australia), to English-medium (Hong Kong), to English as a subjectlanguage (Indonesia.)

\subsubsection{Australia}

As the birthplace of genre-pedagogy, it is no surprise that it has been taken up throughout Australia, albeit to varying degrees. Teachers welcomed the emphasis on teaching a broader range of genres and making their structure explicit; however, they were less likely to address the linguistic side of the approach (Polias \& Dare 2006). Hammond (2012: 233) notes that 'consistent anecdotal evidence suggests that the teaching of text types often results in an overly reductive focus on the structure of reports, narratives, explanations and expositions, with little emphasis on a functional analysis of text patterns or related language features.' The resistance or lack of attention to functional grammar appears to be related to a number of factors including lack of teacher-friendly grammar resources, a political 'back to basics' climate, and lack of systematic teacher development (Polias \& Dare 2006).

One part of Australia that has had notable success with the approach is South Australia (Custance 2006, Polias \& Dare 2006, Fenwick 2010, White et al. 2015). Polias $\&$ Dare (2006) identify three key factors that have supported the success of genrepedagogy in schools in South Australia. The first is development of a pedagogical grammar that 'recontextualizes' functional grammar with terminology and examples that are accessible to and usable by teachers. The second is development of a teacher development programme, in which teachers learn the grammar and how to use it. (See Language and literacy: Classroom applications of functional grammar Dare \& Polias 2004, which was developed to address these two requirements). The third is the 
development of a set of assessment tools, the ESL Scope and Scales (SACSA n.d.) to document the language development of ESL learners.

The ESL Scope and Scales specifies each genre and the language features related to genre, field, tenor and mode appropriate for each year at school. Custance (2006) describes how teachers in one high-poverty school made use of the Scope and Scales to guide them in mapping the genres and language features to be taught at each grade level.

Fenwick (2010) reports on the success of the Language and Literacy programme with 16 teachers across 9 different subject matters in a secondary school. Results after two years found significant improvement both in the texts students wrote and also in student confidence and attitude. Student success was a key factor in teacher uptake of the approach. She points out that:

Access to new knowledge and theory alone did not result in changed practices within the classroom. Rather, practical strategies, which connected to the theory, needed to be available for teachers to trial within their own learning environments. Only when student outcomes became apparent did the participating teachers become advocates of the approach. (Fenwick 2010: 281)

White et al. (2015) report on six schools in South Australia with high numbers of EAL (English as an additional language) students, that undertook a 'whole school' approach to literacy using genre-pedagogy. The article focuses 'specifically on the diagnostics that were developed as part of this programme for tracking and assessing student literacy development.' (p.260). The authors discuss three sets of data. The first makes use of 500 'pre-teaching' and 'post-teaching' texts written by the students and evaluated using the ESL Scope and Scales.

It was found that in $98 \%$ of cases, there was a progression of at least two scales from the pre- to the post-teaching writing, with the writing of some students progressing by as much as five scales. (p.262).

They also gathered longitudinal data over six years, from 2005 to 2011, based on analyzing sets of texts at the end of the school year. They found that students improved by at least one scale per year, (noting that this is an expected outcome for 'mainstream' students, but not frequently for ESL students), with multiple-scale improvements each 
year often the case, especially after two or three years of involvement in a literacy development programme at one of the schools.

Finally, data from the result of standardized tests taken by students in three of the schools showed that these schools outperformed similar schools in Australia on all three areas of literacy covered in the tests: reading, writing and grammar. The authors point out that the success they describe cannot necessarily be attributed to the use of genrepedagogy, but that there is a strong likelihood it played a role. The key, in their view, is that the curriculum - what students are expected to learn, and the pedagogy that guides them should be made explicit.

\subsubsection{Hong Kong}

Although there is no explicit focus on genre-pedagogy in the Hong Kong English curriculum (Maxwell-Reid 2014), one component is to produce texts 'Using appropriate tone, style and register, as well as the salient features of different genres' (Lee 2012: 123). As in most secondary contexts, the focus is on learning content and explicit attention to reading and writing skills is lacking. Writing is generally produced in response to a prompt and then marked according to general categories of organisation and topic development on the one hand, and detailed grammar and spelling mistakes on the other (Lee 2012). In order to investigate students' use of academic language Walker (2010) used an SFL framework to analyze an example of a first-year senior secondary student's response to a prompt in a science class in contrast to a model response. She found that there was a significant gap between the student's writing and the model response in terms of technical nouns and nominalization, use of tense, and inappropriate referencing.

From 2000 to 2009, the Education Bureau of Hong Kong funded programmes designed to introduce small groups of secondary school teachers from English-medium schools to genre-pedagogy, using the Language and Literacy programme developed in South Australia (Polias 2011). An initial intention of the project was for English language teachers and teachers of other subjects to come to a shared understanding about language so that they could collaborate to maximize student learning (Polias 2005). Problems that had been identified were difficulty in explaining abstract concepts in English and teacher- 
fronted classes with little student interaction (Hong Kong Education Bureau n.d.). The programmes introduced teachers to genres specific to their subject matter, genre structure and functional grammar, as well the teaching-learning cycle. They then applied what they had learned in their classrooms in ways they deemed appropriate. In a 2007 report, Polias uses a biology teacher's lesson plan to illustrate the way her explicit focus on language (modality) helped students express their understanding of content in nuanced ways. He notes that 'It is possible with functional perspectives on language to discuss not only what meanings an author is making in a text but also which language resources are being used to make those meanings.' (2007:10) but cautions that functional grammar can be confusing initially and needs to be introduced gradually. He also notes that teachers tend to move from modeling a genre to independent construction, thus not providing students with the necessary support of the 'joint construction' phase.

On a much smaller scale, two reports on the use of genre-pedagogy with four groups of lower secondary students (Lee 2012, Fan 2014) conclude that students made observable gains in their writing when comparing the textual structure, text cohesion, syntax and lexis of the pre-intervention and post-intervention student texts. Subject teachers who observed the intervention conducted by Fan, while generally positive about its effectiveness in developing academic literacy were not convinced they could 'take care of students' language needs as they might not be able to cover the contents before examinations, according to the tight learning schedule of students' (Fan 2014: 91).

Students beginning instruction in English in all or some of their subjects must make the bridge to learning through English (Lin 2012.) These examples suggest that the use of genre-pedagogy has potential to support instruction in English medium classes in contexts like Hong Kong. As in Australia, this means that subject teachers need to add genre-based literacy skills to their teaching repertoire, which may create a tension between time devoted to teaching content and teaching literacy skills. An additional tension is that between teaching and evaluating writing in ways at odds with how it is evaluated on standardized exams (Lee 2012.) A major difference between Australia and Hong Kong is that the majority of teachers in Hong Kong are teaching their subject in English, which is for them an additional language, as it is for their students. 


\subsubsection{Indonesia}

Indonesia has experienced three educational reforms in the last twelve years (Widodo 2016). Genre-based pedagogy based on 'systemic functional grammar' was introduced into the Indonesian English language curriculum during the curriculum reform of 2004. It was reflected specifically in goals for listening, speaking, reading and writing that referred to 'ideational, personal and textual meaning in different genres and text types' (Widodo 2016: 132). It also introduced the 'teaching-learning' curriculum cycle (Luardini \& Asi 2014). Twelve genres were included in the curriculum. According to Sukyadi (2014), the results were mixed, and mostly negative. Some of the issues included introduction of a new metalanguage for teachers with varying degrees of competence in English, confusion about the relationships among genres, lack of understanding of how to teach the same genre in different semesters, and not knowing how to sequence the stages of the teaching-learning cycle within class periods.

The 2006 reform gave schools autonomy in designing curriculum and materials at the local level, in accordance with competency guidelines based on the 2004 curriculum (Widodo 2016.) Teachers worked in local teams to develop syllabi and materials.

Nevertheless, centrally administered language examinations did not reflect the core of the curriculum and so 'English teachers skewed their instruction to national examinations' (Widodo 2016: 134).

Teacher preparation was a key factor explored in three small-scale studies by Omoetan (2008), Pribady (2012) and Luardini \& Asi (2014). Pribady's study of a grade 8 teacher in Bandung found that she had a good understanding of the curriculum cycle and was able to use it effectively to teach the narrative genre. An analysis of student texts showed that they had understood both the stages of a narrative and the use of specific linguistic features such as past tense and a variety of process types (e.g. dialogue, action).

The teachers in Omoetan's study at a senior high school in Surakarta, Central Java, reported that the genre approach required more planning than the previous themebased curriculum because they had to master the various text types, find examples, and develop student activities for each one. They benefited from sharing knowledge in the local teams. They were positively disposed to the approach, but found the complexity of functional grammar to be a problem along with lack of time for students to master each 
genre. The teachers used, but did not always follow the 'teaching-learning' curriculum cycle. For them, the aim of a genre approach was for students to be able to differentiate between the different genres.

Taking a different approach, Luardini \& Asi (2014) evaluated narrative texts written by four junior high school teachers in Central Kalimantan who had post-graduate degrees and had been teaching English at lower secondary for five years. The authors used SFL criteria to analyze the text structure and linguistic features. The narratives were found to have a minimum competence in meeting the criteria. The authors raise the question of how teachers with minimum competence in a genre can be expected to teach it to students.

Although these studies are small-scale and highly localized, they suggest that the success of the approach is dependent on a complex of factors that will be familiar to those who research educational reform, and are reminiscent of the factors identified above for CLT, including adequate, sustained support for teachers to learn about genre, the functional grammar that underlies it as well as the pedagogy; shifts in policy that undermine continuity of support; appropriate materials; teacher basic language proficiency; and dissonance between the national exam and the purported aims of the curriculum.

There is a significant difference, however, that places a different kind of burden on the teachers in Indonesia versus the teachers in Hong Kong. In Indonesia, the curriculum is genre-driven--teachers are expected to teach twelve genres and find appropriate models of each in order to teach them. In Hong Kong genre and subject matter go hand in hand and genre-pedagogy is a way for the subject teacher to make the role of language visible as part of learning subject matter. The teachers in Hong Kong have the same challenges of learning the stages and linguistic features, and scaffolding learners, but they have the subject matter and possible materials at hand.

\section{Content and Language Integrated Learning}

\subsection{Introduction}

Content and Language Integrated Learning (CLIL) has its origins in Europe in the 1990 's. In the context of the European quest for integration, CLIL was seen as a way to 
foreground multilingualism as an integrating educational force, to enhance foreign language education and to introduce innovative classroom pedagogies in content subjects. (Dalton-Puffer et al. 2014: 214).

The name CLIL encapsulates the foundations and the dilemmas of this approach: the duality of subject matter, that it is both content and language; and the aim of learning, to integrate the two. The relationship between content and language and how they are learned and assessed are central concerns in the approach. The way the relationship is instantiated in the curriculum varies widely. The consensus seems to be that content drives the approach (e.g. Coyle, Hood \& Marsh 2010, Dalton-Puffer \& Smit 2013). In other words, the aim is to learn content through an L2, and to achieve some level of bilingualism in the process. The teachers are typically content teachers who themselves are teaching through an L2. 'Language-driven' CLIL, by contrast, is taught by foreign language teachers who use content in their teaching to make learning meaningful (Coyle et al. 2010). Some would argue that 'language-driven' CLIL is outside the CLIL umbrella because it aims at language gains, through the vehicle of content, rather than content gains through a 'vehicular language' (Ioannou Georgiou 2012). Massler, Stotz \& Queisser (2014) suggest, at least for primary schools, that there are three variants of CLIL: CLIL in subject lessons, CLIL in foreign language lessons, and CLIL as a subject of its own, of which the third is relatively rare.

CLIL programmes have spread throughout Europe and beyond. Although the 'language' in CLIL is understood as a foreign, second or heritage language, in practice most programmes have been in English and much of the research has been about English (Dalton-Puffer \& Smit 2013). Programmes and methodologies vary greatly, and some have criticized the hybrid, umbrella nature of CLIL as an obstacle to theorizing and research (Cenoz, Genesee \& Gorter 2013). Although research on CLIL is now being conducted worldwide, the next section will focus on CLIL in Europe as it can provide both 'historical' and current perspectives on the issues.

\subsection{Curriculum framework}

5.2.1 The subject matter and how it is learnt View of language 
In CLIL, language is both the medium through which the content is learned, and is also a focus of learning. Theorizing about language in CLIL has developed in tandem with practice. Coyle et al. (2010), key proponents of the approach, have conceptualized language in CLIL as having three dimensions: the language OF learning (the language needed to access and understand the subject); the language FOR learning (the language needed to operate in the class); and language THROUGH learning (the language that develops in formulating new understandings of the content.) These three dimensions are meant to guide teachers in setting language objectives for their students. There appears to be a wide range of ways to formulate these objectives. Examples given include traditional grammar, lexis, functions, four skills related to text types, to name a few.

More recently, language has been conceptualized in line with systemic functional/genre views and conversational analysis. For example, Llinares, Morton \& Whittaker define language in two ways, 'that which is involved in representing the meanings which are crucial to any academic subject, and that which is used in organizing and orienting the social world of the classroom' (2012: 9). In this view, language is seen in relation to the genres and register (lexicogrammar) specific to the subject being taught, and in relation to ways in which meaning is negotiated in classroom interaction.

Classroom language acquisition

CLIL is based on the notion that language can be acquired in the classroom. According to Navés (2009:25),

Most of the arguments in favour of CLIL come from SLA research and show that CLIL 1) creates conditions for naturalistic language learning; 2) provides a purpose for language use in the classroom; 3) has a positive effect on language learning by putting the emphasis on meaning rather than form; 4) drastically increases the amount of exposure to the target language. (Dalton-Puffer, 2007; Dalton-Puffer \& Smit 2007.)

In other words, the classroom is a natural setting for subject matter learning, of which language is an integral part. The L2 is used to read, write, listen to and talk about the subject matter, thus having both purpose and meaning and providing abundant exposure to language. In effect, understanding of the subject matter is constructed through 
language. The $\mathrm{L} 1$ also plays a role in how language is learned as it may be used to scaffold understanding of concepts in the L2.

From its inception, CLIL has relied on theories of communicative competence and task-based learning as a way to describe the role of language and how it is acquired in the classroom. Ioannou Georgiou, for example, states that 'CLIL brings together the main principles of task-based learning and CLT by creating an authentic setting of meaningful learning where the students can engage in exploring and finding out about the world while using a foreign language to do so' (2012: 496). There is an alternate view of language acquisition in the classroom as acquisition of academic language, and how a given subject matter is constructed/construed through its genres and registers. (Llinares et al. 2012, Lorenzo 2013).

\subsubsection{Needs and roles of learners}

On a macro-level, CLIL is seen as fulfilling two needs at once- the need for the specific subject matter content and the widely perceived need for English as a tool for social, economic and political access and success. At the classroom level, CLIL puts additional demands on learners that they would not have in a purely subject matter or purely FL class: not only do they learn a new subject matter, but they also learn it in English. One rationale for CLIL has been that it is a more motivating way to learn a language than traditional language learning. Whereas traditional language learning does not have immediate application, CLIL has immediate relevance through meaningful cognitive experiences around the subject matter in the L2 (Furlong 2005). According to Lorenzo \& Moore (2010), learners are perceived as language 'novices' (a deficit view) in traditional language classes, while in CLIL classes they are language 'users' (an asset view). Thus 'English in CLIL is more clearly seen as a communicative tool rather than as an expertise in itself' (Hüttner \& Smit 2014: 166).

\subsubsection{Role of the teacher}

Teachers are expected to teach two subjects simultaneously: the content and language. They are not simply teaching content in another language. Given the difference between what learners can do cognitively and represent in their L1 versus in their L2, teachers 
need to be able to, for example, make key concepts of their subject accessible to learners with diverse language competence or to develop learning materials that are both cognitively and linguistically appropriate (Marsh et al. 2010). As the majority of CLIL teachers are subject-matter teachers, not language specialists, they need to have knowledge about language in order to make the language side of learning explicit. Because local subject materials are in the L1, they need to develop their own materials to fit the particular local needs. As a result, teachers play a significant role as curriculum makers in CLIL. Many have also taken on the role of creating collaborative networks through which they share material (Morton 2013).

\subsubsection{Role of context}

Context plays a role in terms of whether CLIL is adopted in the first place, and, if it is, which subjects are taught in English (or another L2), in which grades, for how many years, by whom and how. According to Dalton-Puffer 'In most places, the implementation of CLIL has been fuelled from two directions: high-level policymaking and grass-roots actions, with the latter dovetailing parental and teacher choices'(2011: 134). The huge diversity of CLIL programmes and methodology stems, in part, from its localized origins as a grassroots, experimental approach. Local support of parents and other stakeholders has been a key factor in its success (Navés 2009). The fact that CLIL is most often offered in English is largely due to its perceived value by various stakeholders such as parents, teachers and education authorities (Dalton-Puffer \& Smit 2013). It is now an approach that has become increasingly mainstream and is transitioning from 'being a bottom-up experimental approach to becoming the object of more centralized planning at regional and national levels' (Morton 2013:134).

\subsubsection{Design and organisation of the curriculum}

Organisation and progression of the curriculum

The overall organisation and progression of a CLIL course is largely determined by its subject matter, with language playing a supporting, but critical, role. Curriculum-making thus involves integration of work on language into content development, creation or 
adaptation of materials to meet the linguistic needs of students, and designing learning activities so that students learn the necessary content in English.

An influential framework for integrating content and language in the classroom is the 4 C's framework (Coyle et al. 2010). It comprises content, cognition (thinking and problem solving skills), communication (language knowledge and skills), and culture (awareness of self and other leading to intercultural understanding). Teachers are meant to use the framework to outline objectives related to each ' $\mathrm{C}$ ', including three kinds of language objectives, language FOR, OF and THROUGH learning.

Types of materials and activities

Materials in CLIL must a) convey the content, as locally, regionally or nationally defined, b) do so in the L2 in such a way that students can learn the content and c) in such a way that the language of the content is made visible and learnable. According to Moore \& Lorenzo (2007:29),

One of the biggest challenges for the teacher lies in ensuring that the materials are linguistically accessible (for the level of their learners) and cognitively accessible (for the age of their learners). In tandem, there needs to be a balance between factual information and linguistic illustration.

Of necessity, these materials are adapted from existing materials, or created from scratch. Morton terms this approach to materials 'one of bricolage, as teachers put together texts and activities from various sources and [make] them their own' (2013: 134). As CLIL becomes more centralized, materials are being created to meet local needs.

It is difficult to generalize about the types of materials and activities in CLILthese vary greatly according to different contexts. The need to make meaning clear has brought about an emphasis on multi-modality and multi-media, particularly images, diagrams, graphs and electronic media. Other considerations include the balance of cognitive and language demands, so that activities build on both previous cognitive and linguistic knowledge (Coyle et al. 2010).

5.2.6 Assessment: How is success measured? How is learning/language assessed? 
Because of its dual focus, success in CLIL is measured both in terms of language development and content learning. One issue in assessment is that the relationship between language and content is sometimes assumed and so is not made explicit to students. Content is explicitly assessed, while language is implicitly assessed as the medium through which content learning is demonstrated. While discipline-specific language and concepts are usually made explicit, the language needed to perform discipline-specific tasks such as presenting an oral argument is often invisible (Reierstam 2015). When students lack this language, which constitutes the academic genres and register of the subject, it 'may have considerable implications for students' ability to express content knowledge and to show proof of higher order thinking skills in cognitively demanding tasks' (Reierstam 2015:157). As a result, students with greater linguistic facility but less content knowledge may be judged to know the content better than students with greater content knowledge but less linguistic facility (Hönig 2010). For this reason there has been debate as to whether to conduct assessments in the L1 or whether students can use the L1 to answer questions related to content (Coyle et al. 2010.) Coyle et al. favor the design of assessments in the L2 and suggest that the first step in assessment is to have clear content objectives and clear language objectives, so that assessments can be clearly linked to their achievement.

There is agreement that language is never assessed on its own, but only in relation to the content being learned (Coyle et al. 2010, Llinares et al. 2012, Massler et al. 2014), however there does not appear to be consensus on HOW to describe language or HOW to assess it in relation to content. In the context of secondary schools, Llinares et al. propose the use of integrative tools that clearly link the way in which students will demonstrate understanding of CONTENT (e.g. describing events leading up to a war or comparing two types of government), with the LANGUAGE (both the genre and register/lexicogrammar) that the task requires. Understandings of language are thus internal to the subject matter.

The area of assessment highlights the debates within the CLIL community about how content and language converge in CLIL. In 2011, Dalton-Puffer put it this way: Concerns with theorizing the interaction of language and content are currently becoming a focus of attention for CLIL researchers. Although the most frequently used wording tends to be that of "content and language integration," a more 
appropriate goal, I think, would be to transcend such an understanding that conceptualizes language and curricular content as separate reified entities and instead think of them as one process. (2011:196.)

5.3 The CLIL approach in practice

\subsubsection{CLIL in Europe}

As outlined in the previous section, CLIL as language curriculum has its origins in the policies of the European Union with the European Commission's objective of all European citizens being proficient in three community languages (the mother tongue plus two) (Méndez García 2013) and its explicit recognition of the role of CLIL in achieving these language learning goals (Hüttner, Dalton-Puffer \& Smit 2013). However, whilst numerous EU policies and documents aim to promote plurilingualism through the introduction of CLIL into education systems, there are few, if any, guidelines about how this is to be achieved. As a result, CLIL has so far generally not become well-established in the national education systems of EU member states, remaining more a grass roots movement with the exceptions of the Netherlands and Spain (Hüttner, Dalton-Puffer \& Smit 2013). However, there are signs that this is changing, as Italy, for example, made CLIL compulsory in secondary education in 2012 and in primary schools in 2015, although it is not clear to what extent this has been implemented in practice.

Whether implemented top-down or bottom-up, there is little doubt that CLIL is becoming increasingly popular in many countries in Europe. Although research on the implementation of CLIL curricula is perhaps not as widespread and certainly not as widely published in international peer-reviewed journals as might be expected, a number of scholars are working in this area and we are beginning to see some published results from a variety of contexts, including Italy (see, for example Infante, Benvenuto \& Lastrucci 2008; Aiello, Di Martino \& Di Sabato 2015), Germany (see, for example, Breidbach \& Viebrock 2012), and Austria (see, for example Hüttner et al. 2013), as well as comparative studies (see, for example Sylvén 2013). The 2013 special issue of the International Journal of Bilingual Education and Bilingualism dedicated to CLIL has articles about implementation in nine European Union states (Austria, Finland, Germany, Italy, the Netherlands, Poland, Spain, Sweden, and UK) and the International CLIL 
Research Journal began publication in 2012, testament to the growing interest in research in this area.

In our consideration of the implementation of CLIL curricula, we take Spain as a case study because, as Coyle (2010 viii) states:

Spain is rapidly becoming one of the European leaders in CLIL practice and research. The richness of its cultural and linguistic diversity has led to a wide variety of CLIL policies and practices which provide us with many examples of CLIL in different stages of development that are applicable to contexts both within and beyond Spain.

However, it must also be recognised that the Spanish education system presents a number of characteristics that may distinguish it from other contexts, and which may make CLIL more successful here than elsewhere, especially in terms of policy framework and teacher education, two of the four factors identified by Sylvén (2013) as contributing to the success or otherwise of CLIL. We discuss these factors in more detail below.

\subsubsection{CLIL in Spain}

Spain consists of 17 autonomous regions, split into 50 provinces, plus the two autonomous cities of Ceuta and Melilla and, while there is a central law that gives an overall framework to education, its administration is left to the autonomous regions (Muñoz \& Navés 2009; Ruiz de Zarobe \& Lasagabaster 2010). As a result, there is a huge variety of models for CLIL implementation, which is seen as a distinctive feature of Spanish CLIL (Ruiz de Zarobe \& Lasagabaster 2010; Pérez-Cañado 2012). Another characteristic of the Spanish context that influences language-in-education policies is that some of the autonomous regions have their own official language alongside Spanish, so there is a long-standing culture of bilingualism, while others are essentially monolingual (Fernández Fontecha 2009).

Two main CLIL contexts and models of implementation have been identified by Ruiz de Zarobe \& Lasagabaster (2010a).

1. In mainly monolingual areas where Spanish is the official language and where students are taught through Spanish and one or two foreign languages. 
2. In bilingual communities where there are two official languages - Spanish and the regional language (Basque, Catalan, Galician and Valencian) and schooling takes place in both official languages plus one or two foreign languages.

Muñoz \& Navés (2009) identify a tripartite division according to the overarching aim of the CLIL programme:

1. Improving the English language competence of school children. This is the case in the Comunidad de Madrid, for example, which, building on the previous bilingual and bicultural project agreed between the Spanish government and the British Council increased the number of schools offering CLIL from 13 to 114 in 2007.

2. Promoting multilingualism in mainly monolingual areas. Muñoz \& Navés (2009) give Andalucia's Plan de fomento del plurilingüismo of 2005 as an example, which led to all new schools having at least one bilingual section, the introduction of the first foreign language in infant school and a second foreign language from $5^{\text {th }}$ grades.

3. Enhancing multilingualism in areas that are already bilingual, as in the Comunidad Autónoma del País Vasco (BAC). The Basque government has introduced four projects to promote multilingualism through CLIL at all levels of schooling (see Ruiz de Zarobe \& Lasagabaster 2010b for details).

There is no space in this review to go into details of all the projects in the various regions, but Ruiz de Zarobe \& Lasagabaster (2010) gives a good overview with seven chapters detailing the implementation of CLIL in six different areas of Spain.

Some of the main variables that differ across the different contexts are: the amount of teaching in the foreign language, the number and types of subjects taught through the foreign language, the language level required for both teachers and students, and the length of experience of CLIL (Pérez-Cañado, 2012). There are also factors around whether and how children are selected for inclusion in CLIL streams (see, for example, Lasagabaster and Sierra 2010), and who teaches the CLIL classes, whether it is the subject teacher, the language teacher or both. As part of the Plan de fomento del plurilingüismo in Andalucia, for example, native speaker language assistants have been hired to work alongside subject teachers in a team-teaching model (Lorenzo 2010). 
As mentioned above, there are specificities of the education system in Spain which may make CLIL more successful than elsewhere. One factor is the long-standing experience of Spain with bilingual education. Regional languages as the medium of instruction have been supported since the 1980's and, as Ruiz de Zarobe \& Lasagabaster (2010a:x) note, this has had a double influence on the spread of CLIL. Firstly, experiences of bilingual education in bilingual communities mean that there is longstanding expertise and experience amongst teachers in those communities in appropriate methodologies for teaching in more than one language. Introducing the foreign language alongside the regional language does not, therefore, represent a major shift in teaching practices. Secondly, the experience of bilingual communities can also represent a good example for monolingual educational settings introducing bilingual curricula for the first time. Moreover, there appear to have been programmes of teacher training to ensure that teachers have both the language and the pedagogical skills necessary for implementing CLIL programmes (see the chapters in Ruiz de Zarobe \& Lasagabaster 2010), although these may not always be adequate (see below).

Research on CLIL in Spain has, perhaps unsurprisingly, focused on learning outcomes and the attainment levels of children learning in CLIL and non-CLIL classrooms, and research groups have tended to be concentrated in bilingual settings where bilingual education is more established (see Bruton 2011; Pérez-Cañado 2012 for an overview). Results published generally seem to point to the success of CLIL programmes, with students making significant language gains over their non-CLIL counterparts while performing at least as well in subject content. However, the research has proved controversial both in terms of the research methodology applied and in terms of the claims made for CLIL. These are contested on the grounds that programmes being implemented are not actually CLIL in that they focus on language learning rather than content, and that apparent gains may be due to other factors such as greater exposure to the target language and selectivity in who takes part in CLIL courses (see Lorenzo, Casal \& Moore 2010; Bruton 2011, 2013; Hüttner \& Smit 2014). Lasagabaster and Sierra (2010) point out for example that, while immigrant children are enroled on immersion programmes in the bilingual autonomous regions, they are rarely allowed to take part in CLIL programmes. In the BAC, children wanting to take part in CLIL streams were 
tested in Spanish, Basque and English, with immigrant children usually excluded because they failed to meet the minimum level in Basque, giving weight to accusations that CLIL is elitist.

Most of what has been written about CLIL in Spain paints a predominantly positive picture and there appears to be very little research evidencing challenges faced in its implementation but whether this is due to lack of research or lack of challenges is unclear. Although not research-based, Pavón Vázquez \& Rubio (2010) recognise three problematic areas in CLIL implementation: structural (organisation and sequencing of the curriculum), linguistic (the language level of teachers and students) and attitudinal (particularly on the part of teachers). These are all areas that would merit further research (but see Pérez Cañado 2016 for a report on research projects into some of these issues) .

Pladevall-Ballester (2015), citing Halbach (2009) lists difficulties in implementing CLIL as the need for teaching methods that cater for children's cognitive and linguistic abilities, issues around L1 development and literacy skills, the lack of appropriate teaching materials and teacher training. These challenges are very similar to the list of challenges faced in the implementation of CLT, perhaps unsurprisingly given the similarities between the two approaches with their common focus on meaning and communication.

Some of the chapters in Ruiz de Zarobe \& Lasagabaster (2010) recognise difficulties in teacher training for CLIL and Ruiz de Zarobe \& Lasagabaster (2010a) acknowledge that, while teachers involved in regional language immersion programmes have been able to make the shift relatively smoothly, in other communities 'the teaching curve both for teachers and administrators has been steep' (p. xii). Fernandez \& Halbach (2011) investigated the attitudes of teachers towards the Madrid bilingual project after 4 years of implementation. Their findings were generally positive. However, while teachers felt their training was sufficient, the researchers found fundamental misunderstandings of the theoretical underpinnings of CLIL. Their conclusion is that more, and more appropriate training is necessary for teachers. The content teachers in Guillamón-Suesta \& Renau's (2015) study expressed concern over their own levels of English and felt that they did not have the confidence to teach in a foreign language. These studies indicate, as 
with CLT, that appropriate training on both language and methodology is needed for successful implementation.

A lack of suitable materials has also been identified as a major obstacle (Fernandez \& Halbach 2011). Lorenzo (2010) mentions the lack of textbooks for CLIL and the time needed for preparing teaching materials as an obstacle for teachers, something he notes that native speaker language assistants, hired as part of Andalucía's Plan de fomento del plurilinguismo, have been useful for.

Finally, the level of the children is also seen as a possible challenge. PladevallBallester (2015) researched the attitudes of different stakeholders - teachers, children and parents - in five primary schools in Catalonia that introduced CLIL for the first time. She found general satisfaction amongst all groups, although with concerns and caveats. Amongst the children, low achievers found it difficult to follow the classes and thought the subject matter was too hard. Concern about the effects of CLIL on low achievers was also expressed by both parents and teachers. The teachers in Guillamón-Suesta \& Renau's (2015) study felt that children's language level was not high enough to enable them to be successful in CLIL. However, it should be noted that not all the teachers in this study had actual experience of CLIL.

One final issue that needs consideration and that has not gained much attention in CLIL research is the ideological aspect of bilingual programmes. Whilst the hegemony of English is mentioned by, for example, Lasagabaster \& Ruiz de Zarobe (2010), it is neither discussed nor problematized. Accusations of elitism and selectivity have plagued the implementation of CLIL and not only in Spain. At a time when academic debate around bilingualism and multilingualism is increasingly focusing on ideologies and social practices through the work of scholars such as Monica Heller (see, for example, Heller \& McLaughlin 2016) and Ingrid Piller (see for example, Piller 2012), it seems unlikely that those working in strong CLIL contexts such as Spain can ignore these debates. One exception is Pastor (2015), who studied classroom practices on the Madrid bilingual project from a critical perspective. She notes that:

Imagining Madrid as bilingual in Spanish and English covers up the multilingual reality of its schools and guarantees the status quo of dominant monolingual ideologies (p. 135). 
More research is certainly needed in this area.

\section{Discussion}

Our analysis of the three approaches has shown that there are a number of similarities and overlaps between them in both the theoretical underpinnings and the success and challenges of implementation. In many ways this is unsurprising as they all have common roots in the shift from structural linguistics to a view of language as a tool for meaningmaking, with concomitant changes in what learners are expected to do with the language through interactions in the classroom. However, there are also a number of important differences.

In the following section we will discuss in more detail the similarities and differences, together with the factors that appear to have an impact on the approaches and their potential for successful implementation.

6.1 'Knowledge about language' in the curriculum

Both genre-based pedagogy and CLIL are based on an assumption that knowledge about language (KAL) (Derewianka 2012) plays a key role in understanding and talking or writing about content. KAL in genre is quite clearly defined and is based on a functional view of language, however, in CLIL it is still open to interpretation. Some versions of CLIL draw loosely on broad categories of language such as grammar and vocabulary, while others draw on a more functional view.

In CLT, knowledge about language is generally construed as knowledge of grammatical systems. As CLT came about in reaction to a purely linguistic view of language, KAL can be seen as a negative, especially in strong versions. Nevertheless, where KAL is evident in curriculum materials in weak versions, it still relies on traditional grammar. A key difference between CLT and the other two approaches is that in the latter, KAL is always connected to subject matter content. In CLT KAL is, in a sense, grafted on to communication-based activities.

6.2 The classroom as the context for language acquisition 
Cummins (2008) has made a useful distinction between two kinds of language at school: basic interpersonal communicative skills (BICS) and cognitive academic language proficiency (CALP). The primary focus of teaching in schools is CALP; BICS are learned in interactions with others on the playground, for example, at lunch or outside school.

Some versions of CLT appear to be concerned with BICs in that they are concerned with communicative competence in SOCIAL situations through authentic, meaningful interactions with others. A key contribution of CLT to language teaching is its focus on interaction, cooperation and use of language within the classroom context. However, the classroom is not a natural environment for a sustained focus on interpersonal communication skills, which makes it difficult to have consistently authentic, meaningful interactions. A shift to task-based learning, by adding in the achievement of an outcome for each task, creates opportunities for more varied, purposeful language use. Nevertheless, there is no overarching path of language acquisition.

Genre-based pedagogy and CLIL, on the other hand, are concerned primarily with CALP. The classroom is a natural context for studying subject matter and thus for learning and using academic language. There is a progression of language acquisition tied to the concepts and genres of the subject. CALP also emphasises the role that cognition plays in learning new content and language.

\subsection{Students' needs and roles}

Genre-based pedagogy in English embedded and EMI contexts and CLIL both focus on school subjects, which students need to learn; thus learning English is a de facto need, as the subject content is taught in English and so without English one can't learn the subject matter. The need for content creates the need for English. In the case of CLIL, however, it could be argued that the sociopolitical pressures connected with the dominance of English have created an artificial need for content in English. In terms of genre-based pedagogy in contexts such as Indonesia, where it is tied to types of texts rather than subject matter, the question arises as to why students need to learn those genres in English. 
In CLT, the need for English is complicated and, perhaps, more abstract. The purpose of learning is to be able to communicate successfully beyond the classroom, and the means is through interactions with the teacher and peers in the classroom. Because primary and secondary school students do not always have clear needs or contexts for 'beyond the classroom' communication, successful implementation of CLT depends partly on ensuring that the focus of tasks and communication activities are tailored to the intrinsic motivation of students through topics of interest to them. Many students will not have any extrinsic motivation to learn English except to pass national examinations, the format of which often militate against CLT.

In CLIL and genre-based pedagogy, students have the role of students in the sense that they are expected to perform tasks that they perform in other subject matter classes. In CLT, students are expected to take on roles and perform tasks that are usually performed outside the classroom, which requires active participation and the use of imagination. Such activities make use of the role of play and pretending 'as if', which are important in human learning. Nevertheless, an overemphasis on make believe can contribute to the abstract or contrived nature of the interactions. On the other hand, CLIL has benefited from CLT methodology that requires students to take an active role in classroom interactions.

In genre pedagogy and CLIL, students are expected to use higher order thinking skills in order to learn the concepts associated with the subject matter. In genre pedagogy, these thinking skills are also directed toward language and talk about language.

\subsection{Teacher's expertise and role}

Each approach is most successful in practice when clear guidance is available and teachers are well-prepared to implement it. The kind of preparation and experience teachers need in order to develop the necessary expertise or knowledge base varies with each approach. In CLIL, and in genre pedagogy in English embedded contexts (e.g. Australia) and in EMI (e.g. Hong Kong), the teacher's first basis of expertise is her subject matter, (e.g. history, science). Thus knowledge about language and methodology to make the content accessible through English is an additional expertise. Moreover, in CLIL and EMI, English is likely to be an L2 for the majority of teachers, so they have a 
double responsibility of teaching their subject in English and learning how to do it in a way that helps their students learn content whilst also learning English. In contexts where English is a subject language and genre-based pedagogy is used (e.g. Indonesia), the teacher's expertise is not likely to be tied to content and so genres are taught on an $a d$ hoc basis as a set of text types.

In CLT, the teacher's expertise is less clearly defined. In some respects, it is related to methodology: how to orchestrate meaningful social interactions. However, the de facto expertise for most of these teachers, for whom English is likely to be an L2, is traditional grammar and knowledge of vocabulary and a repertoire of communicative activities in which the language can be used in context. Interaction in the classroom may be at odds with the classroom culture, which expects teacher-fronted, teacher directed pedagogy. And monitoring such interactions may represent a classroom management problem.

\subsection{Organisation of the curriculum}

In both genre and CLIL, the starting point for the organisation of the curriculum is the subject matter that is being learnt. In CLIL, the curriculum followed is that of the subject content, while in genre, the organising principle is the genres which are identified on the basis of the subject matter.

In CLT the curriculum is organised around the language needed for communication, although we have already seen how this is difficult to define. In practice, the communicative curriculum may use a variety of language features as its organizing principle, including skills and micro-skills, functions and notions or, especially in weak versions, traditional grammar.

The three approaches can therefore be seen on a continuum from subject to language in their organisation of the curriculum with CLIL at the subject end, CLT at the language end and genre somewhere in the middle.

\subsection{How success is measured}

In genre-based pedagogy and CLIL, students are assessed based on their understanding and production of subject matter knowledge through English. Success in language is 
directly addressed in the former through rubrics that make the organisation and language features of each genre explicit. In CLIL, how or whether to assess language directly is still a contested area.

In CLT, it is much more difficult to measure success as it is tied to skill in interaction, not to specific language or content. High stakes exams often focus on something more measurable, i.e. grammar knowledge and lexicon, so this continues to be an issue for curriculum.

\section{Implications}

Although the three approaches to curriculum that have been reviewed are seen as discrete and alternative ways of viewing the language curriculum, in practice there are numerous overlaps.

They differ in their geographical distribution and the linguistic contexts in which they tend to be concentrated. All three approaches have their origins in a particular context, and, while it would be misleading to identify a particular approach with a particular geographical area, they tend to differ in their current dissemination, or at least in the attention that is afforded to them by scholars in particular contexts. CLT has its origins in western private language schools before spreading to state schools in Europe, but it is now implemented globally in state schools, mainly because of national policy, especially in Asia. Thus its main implementation is now in target-language removed contexts (Graves 2008) that are very distant from its origins. CLIL is also implemented in target-language removed contexts but these were mainly concentrated in Europe, where its origins lie. This could offer at least a partial explanation for its apparently less problematic application. As it spreads further afield, especially to Latin America and to Japan, it will be interesting to see whether different local conditions lead to new challenges. Genre-based pedagogy has very clear origins in the target-language embedded context of Australia, and while it appears to be have been implemented with some success in EMI contexts, it seems to face some of the same challenges as CLT, as it has spread further afield to target-language removed contexts. The implication is that language curricula need to be adapted to local conditions, rather than imported wholesale 
from different contexts. While this may seem obvious, it seems it rarely happens in practice.

Another key area of difference is in the identification of learner needs on which the curriculum can be based. In this sense, CLIL and genre-based pedagogy have more potential for success in schools as needs can be defined through subject matter and the wider school curriculum and are therefore more or less tangible for learners. In contexts where CLT is common, on the other hand, learners may lack opportunities to communicate in English outside the classroom and therefore may not perceive any real need for English, leading to demotivation. Or, if they do, as with students who participate in online gaming, teachers may not know how to integrate these opportunities into classroom work. However, in these same contexts, teaching subject matter through English presupposes a supply of teachers able to do so as well as a willingness to provide the subject matter in a language other than the national one.

A further difference is that genre-pedagogy has clear guidelines for identifying language targets and for assessing learners' progress and achievement with respect to them - this is missing in CLIL and CLT. However, the focus in genre-pedagogy has been mainly on written texts, and not on the kinds of oral interactions that are recognized as important in both CLIL and CLT.

One factor common to all three approaches in determining the success of curriculum innovation is the need for teacher expertise. Although there are differences in the expertise that is required, adequate teacher preparation is essential to successful implementation but this often appears to be lacking. In CLIL and genre-based pedagogy there is the important question around who teaches English, given that the majority of teachers of English in schools are not content specialists but language specialists. Either content teachers need to be prepared with KAL and appropriate CLIL methodologies, or English teachers need to be prepared in the relevant subject-content, or the two teachers need to collaborate and teach alongside each other.

Given the strengths and weaknesses of each approach and the considerable overlaps, it may be opportune to look for alternatives that combine elements of CLT, genre-based pedagogy and CLIL. One possibility would be to build the curriculum around English language arts that encompass a variety of story and literary genres 
(appropriate for the age of the learners), using communicative methodologies, rather than the traditional grammar translation that was the hallmark of early teaching of literature. Language specialists might more reasonably be expected to teach literature than subject matter such as science or history. Another alternative is project-based learning (PBL), which is reasonably well-established as an approach to language learning, although not widely implemented as yet. PBL, especially if made relevant to the wider school curriculum, would enable a more integrated approach to content and language, therefore allowing for learner needs and interests to be defined but without being as closely tied to school subjects as CLIL or genre-pedagogy.

These two alternatives draw on the affordance of subject matter as the basis for meaning-making, cognitive engagement and language development, while recognizing the need for the kinds of interactions and participation that communicative methodologies provide.

\section{Further research}

As noted above, there is perhaps less research into CLIL than might be expected, given that it has been implemented in classrooms since the 1990's. The research that has been carried out has focused mainly on learning outcomes, particularly comparing the achievements of CLIL and non-CLIL learners, but there is a growing body of classroombased research that is investigating how CLIL is actually implemented by teachers in their day-to-day practice. Such research will add to the explanatory power for the apparently positive outcomes that are being reported. As CLIL spreads, to Latin America for example, such research will become even more important in order to understand the effects of CLIL on language learning in different contexts.

In CLT, on the other hand, there is abundant research into classroom implementation, which has highlighted the gap between the curriculum and classroom practice, but there is far less research into learning outcomes and learner achievements. Given the complex classroom picture, the rather fuzzy nature of CLT and the difficulties in assessing learning, this is perhaps not surprising, but such research is necessary if we are to gain a better understanding of what learners exposed to a communicative approach to language teaching are actually learning. 
For genre-based pedagogy, more research is needed in contexts such as Hong Kong, where English is the L2 of both teacher and learners, in order to understand the challenges faced by teachers in successfully implementing the approach. Specifically, given teachers' concerns that work on language subtracts from work on content, what kind of KAL is adequate and appropriate for teachers to know and convey to students so that they can successfully understand and interpret the genres through which the subject matter is constructed.

This review has also suggested potential for a new research agenda to explore what each approach can 'learn' from the other to make its implementation in schools more feasible for teachers and more productive for learners. For example, in many CLIL and EMI contexts, learners learn English as a subject in classes that adopt a CLT approach such as meaningful interactions around the accomplishment of tasks. What can the CLIL teacher learn from the English subject teacher and what can the English subject teacher do to support the CLIL teacher? We suggest that the three approaches are best seen in relationship to each other on a set of continua comprising each aspect of the curriculum framework: the subject matter and how it is learnt, needs and roles of learners, role of the teacher, role of context, design and organisation of the curriculum, and assessment. Such a view allows for aspects of each to be integrated according to local conditions and local needs.

\section{Conclusion}

In this review we have examined in detail three current approaches to English language curriculum found in state schools in different contexts around the world. Through our analysis using the curriculum framework we have shown that all three approaches have similar origins and that there are numerous similarities between them, in particular in their view of language as meaning, and in their views of the roles of teachers, learners and learning. However, there are also some important differences especially in the relationship between content and language and in the needs of learners. All three approaches also present challenges, above all for teachers, many of which remain unsolved in spite of 20 or more years of experience in implementation. 


\section{Bibliography}

Adamson, B. \& A. Tong Siu Yin (2008). Leadership and collaboration in implementing curriculum change in Hong Kong Secondary Schools. Asia Pacific Education Review 9.2, 180-189.

Ahn, K. (2011). Learning to teach under curriculum reform: The practicum experience in South Korea. In K. E. Johnson \& P. Golombek (eds.), Research on second language teacher education. New York, NY: Routledge, 239-253.

Aiello, J., E. Di Martino \& B. Di Sabato (2015). Preparing teachers in Italy for CLIL: Reflections on assessment, language proficiency and willingness to communicate. International Journal of Bilingual Education and Bilingualism, DOI:10.1080/13670050.2015.1041873

Alderson, J.C. (2007). The CEFR and the need for more research. Modern Language Journal 91.4, 659-663.

Ali, N.L., M. O. Hamid \& K. Moni (2011). English in primary education in Malaysia: Policies, outcomes and stakeholders' lived experiences. Current Issues in Language Planning 12.2, 147-166.

Baker, W. (2008). A critical examination of ELT in Thailand: The role of cultural awareness. RELC Journal 39.1, 131-146.

Baldauf, R.B., R.B. Kaplan, N. Kamwangamalu \& P. Bryant (2011). Success or failure of primary second/foreign language programmes in Asia: What do the data tell us? Current Issues in Language Planning 12.2, 309-323.

Block, D., J. Gray \& M. Holborow (2012). Neoliberalism and applied linguistics. London: Routledge.

Breidbach, S. \& B. Viebrock (2012). CLIL in Germany: Results from recent research in a contested field of education. International CLIL Research Journal 1.4, 5-16.

Brisk, M. E. (2015). Engaging students in academic literacies: Genre-based pedagogy for K-12 classrooms. New York: Routledge.

Brown, H.D. (2007). Teaching by principles (3rd edn). White Plains, NY: Pearson Education. 
Bruton, A. (2011). Is CLIL so beneficial, or just selective? Re-evaluating some of the research. System 39.4, 523-532.

Bruton, A. (2013). CLIL: Some of the reasons why... and why not. System 41.3, 587597.

Butler, Y.G. (2011). The implementation of communicative and task-based language teaching in the Asia-Pacific Region. Annual Review of Applied Linguistics 31, 3657.

Canale, M. (1983) From communicative competence to communicative language pedagogy. In J.C. Richards \& R.W. Schmidt (eds.), (2013) Language and communication. London: Routledge, 2-28.

Canale, M. \& M. Swain (1980). Theoretical bases of communicative approaches to second language teaching and testing. Applied Linguistics 1.1, 1-47.

Cenoz, J., F. Genesee \& D. Gorter (2013). Critical analysis of CLIL: Taking stock and looking forward. Applied Linguistics 35.3, 243-262.

Chen, A. (2011). Parents' perspectives on the effects of the primary EFL education policy in Taiwan. Current Issues in Language Planning 12.2, 205-224.

Christie, F. (2013). Genres and genre theory: A response to Michael Rosen, Changing English 20.1, 11-22.

Clark, U. (2013). A sense of place: Variation, linguistic hegemony and the teaching of literacy in English. English Teaching 12.2, 58-75.

Copland, F., S. Garton \& A. Burns (2014). Challenges in teaching English to young learners: Global perspectives and local realities. TESOL Quarterly 48.4, 738-762.

Coyle, D. (2010) Forward. In Y.R. Ruiz de Zarobe \& D. Lasagabaster (eds.), vii-viii.

Coyle, D., B. Holmes \& L. King (2009). Towards an integrated curriculum-CLIL national statement and guidelines. London: The Languages Company.

Coyle, D., P. Hood \& D. Marsh (2010). CLIL Content and language integrated learning. Cambridge: Cambridge University Press.

Cummins, J. (2008). BICS and CALP: Empirical and theoretical status of the distinction. In B. Street \& N. H. Hornberger (eds.), Encyclopedia of language and education, (2nd edn), Volume 2: Literacy. New York: Springer, 71-83. 
Custance, B. (2006). Whole-school genre maps: A case study in South Australia. In R. Whittaker, M. O'Donnell \& A. McCabe (eds.), Language and literacy: Functional approaches. London: Continuum, 144-158.

Dalton-Puffer, C. (2011). Content-and-language integrated learning: From practice to principles? Annual Review of Applied Linguistics 31, 182-204.

Dalton-Puffer, C., A. Llinares, F. Lorenzo \& T. Nikula (2014). "You can stand under my umbrella": Immersion, CLIL and bilingual education. A Response to Cenoz, Genesee \& Gorter (2013). Applied Linguistics 35.2, 213-218.

Dalton-Puffer, C. \& U. Smit (2013). Content and language integrated learning: A research agenda. Language Teaching 46.4, 545-559.

Dare, B. \& J. Polias (2004). Language \& literacy: Classroom applications of functional grammar. South Australia: Department of Education and Children's Services.

Davison, C. \& C. Leung (2009). Current issues in English language teacher-based assessment. TESOL Quarterly 43.3, 393-415.

Derewianka, B. (2003). Trends and issues in genre-based approaches. RELC Journal $34.2,133-154$.

Derewianka, B. (2012). Knowledge about language in the Australian Curriculum: English. Australian Journal of Language and Literacy 35.1, 127-146.

Dix, S., G. Cawkwell \& T. Locke (2011). New Zealand's literacy strategy: A lengthening tail and wagging dogs. In A. Goodwyn \& C. Fuller (eds.), The great literacy debate. London: Routledge, 87-105.

Edge, J. \& S. Garton (2009). From experience to knowledge in ELT. Oxford: Oxford University Press.

Enever, J. \& J. Moon (2009). New global contexts for teaching Primary ELT: Change and challenge. In J. Enever, J. Moon \& U. Raman (eds.), Young learner English language policy and implementation: International perspectives. Reading: Garnet Education, 5-21.

Fan, C. (2014). The effectiveness of genre-based pedagogy in developing students' academic literacy in Hong Kong EMI secondary schools. MA Thesis, University of Hong Kong. http://hdl.handle.net/10722/209663. 
Fenwick, L. (2010). Initiating and sustaining learning about literacy and language across the curriculum within secondary schools. Australian Journal of Language and Literacy 33.3, 268-283.

Fernandez, R. \& A. Halbach (2011). Analysing the situation of teachers in the Madrid bilingual project after four years of implementation. In Y. Ruiz de Zarobe, J. Sierra, \& F. Gallardo del Puerto (eds.), Content and foreign language integrated learning. Contributions to multilingualism in European contexts. Bern: Peter Lang, 241-270. Fernández Fontecha, A. (2009). Spanish CLIL: Research and official actions. In Y. R. de Zarobe \& R.M. Jiménez Catalán (eds.), Content and language integrated learning: Evidence from research in Europe. Bristol: Multilingual Matters, 3-21.

Furlong, A. (2005). The central role of language learning/teaching methodologies in CLIL http://archive.ecml.at/mtp2/CLILmatrix/pdf/wsrepD3E2005 6.pdf The CLIL quality matrix, Central workshop report 6/2005(Graz, Austria, 3-5 November 2005) Garton, S. (2014). Unresolved issues and new challenges in teaching English to young learners: The case of South Korea. Current issues in language planning 15.2, 201219.

Garton, S., F. Copland \& A. Burns (2011). Investigating global practices in teaching English to young learners. British Council ELT Research Papers 11-01. London: British Council.

Gaynor, B. (2014). From language policy to pedagogic practice: Elementary school English in Japan. In S. Rich, (ed.), International perspectives on teaching English to young learners. Basingstoke: Palgrave Macmillan UK, 66-84.

Gebhard, M., I. A. Chen \& L. Britton (2014). Miss, nominalization is a nominalization: English language learners' use of SFL metalanguage and their literacy practices. Linguistics and Education 26, 106-125.

Gibbons, P. (2009). English learners, academic literacy, and thinking: Learning in the challenge zone. Portsmouth, NH: Heinemann.

Gibbons, P. (2015). Scaffolding language, scaffolding learning ( $2^{\text {nd }}$ edn). Portsmouth, NH: Heinemann.

Gilmore, A. (2007). Authentic materials and authenticity in foreign language learning. Language Teaching 40.2, 97-118. 
Graddol, D. (2006). English next. London: British Council

Graves, K. (2016). Language curriculum design: Possibilities and realities. In G. Hall (ed.), Routledge handbook of English language teaching. London: Routledge, 79-94.

Graves, K. (2008). The language curriculum: A social contextual perspective. Language Teaching 41.2, 147-181.

Guillamón-Suesta, F. \& M. L. R. Renau (2015). A critical vision of the CLIL approach in secondary education: A study in the Valencian Community in Spain. Latin American Journal of Content \& Language Integrated Learning 8.1, 1-12.

Halliday, M.A.K. \& C. M. Matthiessen (2004). An introduction to functional grammar $\left(3^{\text {rd }}\right.$ edn). London: Arnold.

Hamid, O.M. \& E. Honan (2012). Communicative English in the primary classroom: Implications for English-in-education policy and practice in Bangladesh. Language, Culture and Curriculum 25.2, 139-156.

Hammond, J. (2012). Hope and challenge in the Australian Curriculum: Implications for EAL students and their teachers. Australian Journal of Language and Literacy 35.1, 223-240.

Hardman, J. \& N. A-Rahman (2014). Teachers and the implementation of a new English curriculum in Malaysia. Language, Culture and Curriculum 27.3, 260-277.

Heller, M., \& M. McLaughlin (2016). Language choice and symbolic domination. In S. Wortham, K. Deoksoon \& S. May (eds.), Discourse and Education. Springer Living Reference Work, 1-9.

Hong Kong Education Bureau. (n.d.) Improving language and learning in public-sector schools (ILLIPSK) (Archive) http://www.edb.gov.hk/en/sch-admin/sch-qualityassurance/professional-support-online-resources/lang-support-emi-edu/illips

Hönig, I. (2010). Assessment in CLIL: Theoretical and empirical research. VDM Publishing.

Hüttner, J., C. Dalton-Puffer \& U. Smit (2013). The power of beliefs: Lay theories and their influence on the implementation of CLIL programmes. International Journal of Bilingual Education and Bilingualism 16.3, 267-284. 
Hüttner, J. \& U. Smit (2014). CLIL (Content and language integrated learning): The bigger picture. A response to: A. Bruton. 2013. CLIL: Some of the reasons why and why not. System 44, 160-167.

Hymes, D. (1972). On communicative competence. In J.B. Pride \& J. Holmes (eds.), Sociolinguistics. Harmondsworth: Penguin, 269-293.

İnal, D. (2009). The early bird catches the worm: The Turkish case. In J. Enever, J. Moon \& U. Raman (eds.), Young learner English language policy and implementation: International perspectives. Reading: Garnet Education, 71-78.

Infante, D., G. Benvenuto \& E. Lastrucci (2008). Integrating content and language at primary school in Italy: Ongoing experimental research. International CLIL Research Journal 1.1, 74-82.

Ioannou Georgiou, S. (2012). Reviewing the puzzle of CLIL. ELT Journal 66.4, 495504.

Kang, D-M. (2008). The classroom language use of a Korean elementary school EFL teacher: Another look at TETE. System 36, 214-226.

Kantarcioglŭ, E. \& S. Papageorgiou (2012). The Common European Framework of Reference. In C. Coombe, P. Davidson, B. O'Sullivan \& S. Stoynoff (eds.), The Cambridge guide to second language assessment. Cambridge: Cambridge University Press, 82-88.

Larsen-Freeman, D. \& D. Freeman (2008). Language moves: The place of languages foreign and otherwise - in classroom teaching and learning. In J. Greene, G. Kelly \& A. Luke. (eds.), Review of Research on Education 32.1, 147-186.

Lasagabaster, D. \& Y. Ruiz de Zarobe (2010). Ways forward in CLIL: Provision issues and future planning. In Y. Ruiz de Zarobe \& D. Lasagabaster (eds.), 278-295.

Lasagabaster, D., \& J. M. Sierra (2010). Immersion and CLIL in English: More differences than similarities. ELT Journal 64.4, 367-375.

Lee, I. (2012). Genre based teaching and assessment in secondary English classrooms. English Teaching: Practice and Critique 11.4, 120-136.

Lin, A. (2012). Multilingual and multimodal resources in genre-based pedagogical approaches to L2 English content classrooms. In C. Leung \& B. V. Street (eds.), English: A changing medium for education. Bristol: Multilingual Matters, 79-103. 
Lin, A.M.Y. (2010). Curriculum: Foreign language learning. In P. Peterson, E. Baker \& B. McGaw (eds.), International encyclopedia of education volume 1 ( $\left.3^{\text {rd }} \mathrm{edn}\right)$. Oxford: Elsevier, 428-434.

Llinares, A., T. Morton \& R. Whittaker (2012). The roles of language in CLIL. Cambridge: Cambridge University Press.

Little, D. (2007). The Common European Framework of Reference for Languages: Perspectives on the making of supranational language education policy. Modern Language Journal 91.4, 645-655.

Lorenzo, F. (2010). CLIL in Andalusia. In Y. Ruiz de Zarobe \& D. Lasagabaster (eds.), $2-11$.

Lorenzo, F. (2013). Genre-based curricula: Multilingual academic literacy in content and language integrated learning. International Journal of Bilingual Education and Bilingualism 16.3, 375-388.

Lorenzo, F., S. Casal \& P. Moore (2010). The effects of content and language integrated learning in European education: Key findings from the Andalusian bilingual sections evaluation project. Applied Linguistics 31.3, 418-442.

Lorenzo, F. \& P. Moore (2010). On the natural emergence of language structures in CLIL: Towards a theory of European educational bilingualism. In C. Dalton-Puffer, T. Nikula \& U. Smit (eds.), Language use and language learning in CLIL classrooms. Philadelphia: John Benjamins, 23-38.

Luardini, M. A. \& N. Asi (2014). An analysis of linguistic competence in writing texts by teachers in Palangka Raya. International Journal of English and Education 3.2, 8094.

Marsh, D., P. Mehisto, D. Wolff \& M. J. Frigols Martin (2010). European framework for CLIL teacher education: A framework for the professional development of CLIL teachers. Graz: European Centre for Modern Languages.

Martin, J. R. (2009). Genre and language learning: A social semiotic perspective. Linguistics and Education 20, 10-21.

Massler, U., D. Stotz, \& C. Queisser (2014). Assessment instruments for primary CLIL: The conceptualisation and evaluation of test tasks. The Language Learning Journal $42.2,137-150$. 
Maxwell-Reid, C. (2014). Genre in the teaching of English in Hong Kong: A perspective from systemic functional linguistics. In D. Coniam (ed.), English language education and assessment: Recent developments in Hong Kong and the Chinese mainland. Singapore: Springer, 87-102.

Méndez García, M. D. C. (2013). The intercultural turn brought about by the implementation of CLIL programmes in Spanish monolingual areas: A case study of Andalusian primary and secondary schools. The Language Learning Journal 41.3, 268-283.

Ministry of Education Singapore (2010). English Language Syllabus 2010. https://www.moe.gov.sg/docs/default-source/document/education/syllabuses/english$\underline{\text { language-and-literature/files }}$

Modiano, M. (2009). EIL, native-speakerism and the failure of European ELT. In F. Sharifian (ed.), English as an international language: Perspectives and pedagogical issues. Bristol: Multilingual Matters, 58-77.

Moore, J. \& M. Schleppegrell (2014). Using a functional linguistic metalanguage to support academic language development in the English Language Arts. Linguistics and Education 26, 92-105.

Moore, P. \& F. Lorenzo (2007). Adapting authentic materials for CLIL classrooms: An empirical study. Vienna English Working Papers 16.3, 28-35.

Morrow, K. (2012). Communicative language testing. In C. Coombe, P. Davidson, B. O’Sullivan \& S. Stoynoff (eds.), The Cambridge guide to second language assessment. Cambridge: Cambridge University Press, 140-146.

Morton, T. (2013). Critically evaluating materials in CLIL. In J. Gray (ed.), Critical perspectives on language teaching materials. Basingstoke: Palgrave Macmillan, $111-136$.

Muñoz C. \& T. Navés (2009). CLIL in Spain. Retrieved 24/02/2016 from http://diposit.ub.edu/dspace/bitstream/2445/9142/1/MunozNaves2007.pdf

Navés, T. (2009). Effective content and language integrated learning. In Y. Ruiz de Zarobe \& R. Jiménez Catalán (eds.), Content and language integrated learning: Evidence from research in Europe. Bristol: Multilingual Matters, 22-40. 
Nguyen, H.T.M. (2011). Primary English language education policy in Vietnam: Insights from implementation. Current Issues in Language Planning 12.2, 225-249.

Nunan, D. (2003). The impact of English as a global language on educational policies and practices in the Asia-Pacific region. TESOL Quarterly 37.4, 589-613.

Omoetan, G. Y. (2008). The implementation of genre-based approach in the teaching of English at SMA Negeri 1 Surakarta. Ph.D. dissertation, Sebelas Meret University. https://core.ac.uk/download/files/478/16507883.pdf

Pastor, A. M. R. (2015). The commodification of English in 'Madrid, comunidad bilingüe': Insights from the CLIL classroom. Language Policy 14.2, 131-152.

Pavón Vázquez, V. \& F. Rubio (2010). Teachers' concerns and uncertainties about the introduction of CLIL programmes. Porta Linguarum 14, 45-58.

Pérez Cañado, M. L. (2016). From the CLIL craze to the CLIL conundrum: Addressing the current CLIL controversy. Bellaterra Journal of Teaching \& Learning Language \& Literature, 9.1, 9-31.

Pérez-Cañado, M. L. (2012). CLIL research in Europe: Past, present, and future. International Journal of Bilingual Education and Bilingualism 15.3, 315341.

Piller, I. (2012). Multilingualism and social exclusion. In M. Martin-Jones, A. Blackledge \& A. Creese (eds.), The Routledge handbook of multilingualism. Abingdon: Routledge, 281-296.

Pladevall-Ballester, E. (2015). Exploring primary school CLIL perceptions in Catalonia: Students', teachers' and parents' opinions and expectations. International Journal of Bilingual Education and Bilingualism, 18.1, 45-59.

Polias, J. (ed.) (2005) Improving language and learning in public-sector schools. Hong Kong: Quality Assurance Division, Hong Kong Education and Manpower Bureau. Polias, J. (2007) Lesson observation report for ILLIPS 2007. http://www.lexised.com/resources/

Polias, J. (2011). English language teachers and subject teachers collaborating: Recent changes in pedagogical practices in Hong Kong. Tidsskriftet Viden Om Laesning 10, 22-31. 
Polias, J. \& B. Dare (2006). Towards a pedagogical grammar. In R. Whittaker, M. O’Donnell \& A. McCabe (eds.), Language and literacy: Functional approaches. London: Continuum, 123-143.

Prapaisit de Segovia, L. \& D. M. Hardison (2008). Implementing education reform: EFL teachers' perspectives. ELT Journal 63.2, 154-162.

Pribady, I. Y. (2012). The implementation of a genre based approach to teaching narrative writing. In J. S. Knox (ed.), Papers from the 39th International Systemic Functional Congress. Sydney, 57-62.

Reierstam, H. (2015). Assessing language or content? A comparative study of the assessment practices in three Swedish upper secondary CLIL schools. Licenciate Thesis, University of Gothenburg, Sweden. http://hdl.handle.net/2077/40701

Richards, J. (2013). Curriculum approaches in language teaching: Forward, central and backward design. RELC Journal 44.1, 5-33.

Rose, D. (2015). New developments in genre-based literacy pedagogy. In C. A. MacArthur, S. Graham \& J. Fitzgerald (eds.), Handbook of writing research (2nd edn). New York: Guilford, 227-242.

Rose, D. \& J. Martin (2012). Learning to write, reading to learn: Genre, knowledge and pedagogy in the Sydney School. Sheffield: Equinox.

Rothery, J. (1989). Learning about language. In R. Hasan \& J. R. Martin (eds.), Language development: Learning language, learning culture (vol. 1). Norwood, NJ: Ablex Publishing Corporation, 199-256.

Rothery, J. (1996). Making changes: Developing an educational linguistics. In R. Hasan \& G. Williams (eds.), Literacy in society. London: Longman, 86-128.

Ruiz de Zarobe, Y. \& D. Lasagabaster (eds.) (2010). CLIL in Spain: Implementation, results and teacher training. Newcastle upon Tyne: Cambridge Scholars Publishing. Ruiz de Zarobe, Y.\& D. Lasagabaster (2010a). Introduction. The Emergence of CLIL in Spain: An educational challenge. In Y. Ruiz de Zarobe \& D. Lasagabaster (eds.), ixxvii.

Ruiz de Zarobe, Y. \& D. Lasagabaster (2010b). CLIL in a bilingual community: The Basque autonomous community. In Y. Ruiz de Zarobe \& D. Lasagabaster (eds.), 1225. 
SACSA (South Australian Curriculum Standards and Accessibility) (n. d.) ESL Scope and Scales. http://www.sacsa.sa.edu.au/index_fsrc.asp?t=ECCP\&ID=E8A

Savignon, S. J. (2008). Communicative language teaching: Linguistic theory and classroom practice. In S. J. Savignon (ed.), Interpreting communicative language teaching: Contexts and concerns in teacher education. New Haven, Yale University Press, 1-28.

Schwab, J. (1973). The practical 3: Translation into curriculum. The School Review 81.4, $501-522$.

Schleppegrell, M. (2004). The language of schooling: A functional linguistics perspective. Mahwah, New Jersey: Lawrence Erlbaum Associates.

Seargeant, P. (2008). Ideologies of English in Japan: The perspective of policy and pedagogy. Language Policy 7.2, 121-142.

Stelma, J. (2009). What is communicative language teaching? In S. Hunston \& D. Oakey (eds.), Introducing applied linguistics: Concepts and skills. London: Routledge, 5359.

Sukyadi, D. (2014). The teaching of English in secondary schools in Indonesia. In B. Spolsky \& K. Sung (eds.), Secondary school education in Asia. London: Routledge, $123-147$.

Sylvén, L. K. (2013). CLIL in Sweden-why does it not work? A metaperspective on CLIL across contexts in Europe. International Journal of Bilingual Education and Bilingualism 16.3, 301-320.

Tomlinson, B. (2011). Introduction. In B. Tomlinson (ed.), Materials development in language teaching ( $2^{\text {nd }}$ edn.) Cambridge: Cambridge University Press, 1-33.

Vander Ark, T. (2016). Next-Gen Personalized Learning for ELL Students. Education Week. Accessed 27/04/17 from http://blogs.edweek.org/edweek/on_innovation/2016/02/nextgen_personalized_learning_for_ell_students.html

Walker, E. (2010). A systemic functional contribution to planning academic genre teaching in a bilingual education context. Language Awareness 19.2, 73-87. 
White, P.R.R., G. Mammone \& D. Caldwell (2015). Linguistically based inequality, multilingual education and a genre-based literacy development pedagogy: Insights from the Australian experience. Language and Education 29.3, 256-271.

Widodo, H. P. (2016). Language policy in practice: Reframing the English language curriculum in the Indonesian secondary education sector. In R. Kirkpatrick (ed.), English language education policy in Asia. New York: Springer International Publishing, 127-151.

Yan, C. \& C. He (2012). Bridging the implementation gap: An ethnographic study of English teachers' implementation of the curriculum reform in China. Ethnography and Education 7.1, 1-19.

Zhang, F. \& Y. Liu (2014). A study of secondary school English teachers' beliefs in the context of curriculum reform in China. Language Teaching Research 18.2, 187-204. 